\title{
Chromatin organization changes during the establishment and maintenance of the postmitotic state
}

\author{
Yiqin Ma and Laura Buttitta* [D
}

\begin{abstract}
Background: Genome organization changes during development as cells differentiate. Chromatin motion becomes increasingly constrained and heterochromatin clusters as cells become restricted in their developmental potential. These changes coincide with slowing of the cell cycle, which can also influence chromatin organization and dynamics. Terminal differentiation is often coupled with permanent exit from the cell cycle, and existing data suggest a close relationship between a repressive chromatin structure and silencing of the cell cycle in postmitotic cells. Heterochromatin clustering could also contribute to stable gene repression to maintain terminal differentiation or cell cycle exit, but whether clustering is initiated by differentiation, cell cycle changes, or both is unclear. Here we examine the relationship between chromatin organization, terminal differentiation and cell cycle exit.

Results: We focused our studies on the Drosophila wing, where epithelial cells transition from active proliferation to a postmitotic state in a temporally controlled manner. We find there are two stages of $G_{0}$ in this tissue, a flexible $G_{0}$ period where cells can be induced to reenter the cell cycle under specific genetic manipulations and a state we call "robust," where cells become strongly refractory to cell cycle reentry. Compromising the flexible $G_{0}$ by driving ectopic expression of cell cycle activators causes a global disruption of the clustering of heterochromatin-associated histone modifications such as H3K27 trimethylation and H3K9 trimethylation, as well as their associated repressors, Polycomb and heterochromatin protein 1 (HP1). However, this disruption is reversible. When cells enter a robust $\mathrm{G}_{0}$ state, even in the presence of ectopic cell cycle activity, clustering of heterochromatin-associated modifications is restored. If cell cycle exit is bypassed, cells in the wing continue to terminally differentiate, but heterochromatin clustering is severely disrupted. Heterochromatin-dependent gene silencing does not appear to be required for cell cycle exit, as compromising the H3K27 methyltransferase Enhancer of zeste, and/or HP1 cannot prevent the robust cell cycle exit, even in the face of normally oncogenic cell cycle activities.
\end{abstract}

Conclusions: Heterochromatin clustering during terminal differentiation is a consequence of cell cycle exit, rather than differentiation. Compromising heterochromatin-dependent gene silencing does not disrupt cell cycle exit.

Keywords: Drosophila, Cell cycle exit, E2F, Histone modifications, Heterochromatin binding proteins

\section{Background}

Cellular differentiation is the acquisition of cell-type specific characteristics, driven by changes in gene expression. Changes in gene expression are largely controlled by transcription factors, which can be facilitated or impeded

\footnotetext{
*Correspondence: buttitta@umich.edu

Department of Molecular, Cellular and Developmental Biology,

University of Michigan, Ann Arbor, Ml 48109, USA
}

by chromatin modifications, binding site accessibility and chromatin organization. A reciprocal relationship exists between chromatin organization, modification and gene expression, and several studies have shown that chromatin organization and modifications can change during differentiation. For example, during neural differentiation silenced genes move to repressive compartments in the nucleus [1-3]. In certain contexts of differentiation, global nuclear compartments can become dramatically 
reorganized to facilitate specialized functions [4]. At a more local level, chromatin modifiers can be recruited to specific genes involved in differentiation to facilitate their expression and limit the expression of genes involved in other cell-type programs that must be kept off [5]. Thus, dynamic changes in chromatin organization and modification can have critical consequences on proper differentiation during development.

There is also an intimate relationship between the cell cycle and chromatin organization and modifications. Chromatin in actively cycling cells is highly dynamic. During S-phase, new histones are incorporated onto nascent DNA requiring re-establishment of histone modifications [6]. During mitosis, nuclear organization including intra- and interchromosomal contacts is lost and many chromatin modifiers are ejected from chromatin to facilitate proper chromosome condensation and segregation $[7,8]$. In addition, the activity of histone modifiers can be regulated in a cell cycle-dependent manner [9-14]. During differentiation cells often transition from rapid proliferation to slower cycling, which can be followed by cell cycle exit or entry into $G_{0}$ coordinated with terminal differentiation. Thus, the modification and organization of chromatin in the nucleus can be impacted by the differentiation process itself, but also by the changes in cell cycle dynamics during differentiation. For example, chromatin compacts and heterochromatin clusters as cells in the embryo cycle more slowly and become lineage restricted [15]. In Drosophila loci within constitutive heterochromatin show increased association in terminally differentiated postmitotic cells [16] and facultative heterochromatin-forming Polycomb bodies cluster as cells differentiate and the cell cycle slows during embryogenesis [17]. Methods such as inducing developmental arrest have been used in attempt to disentangle the influence of cell cycle changes from differentiation process [16], but these approaches cannot fully uncouple terminal differentiation from the accompanying cell cycle exit and it has remained unclear whether changes in heterochromatin clustering and dynamics are due to differentiation, the accompanying cell cycle changes, or both. The influence of cell cycle changes during differentiation adds a layer of complexity to our understanding of the relationship between chromatin organization and modifications and differentiation.

Here we directly address the relationship between heterochromatin organization, chromatin modification and cell cycle exit using the temporally controlled cell cycle exit in the Drosophila wing [18-20]. In our experiments, we take advantage of tools that can effectively uncouple cell cycle exit and differentiation to ask whether heterochromatin clustering is a consequence of cell cycle exit or differentiation. In addition, we examine changes in chromatin modifications caused by the delay of cell cycle exit and examine the impact of disrupting heterochromatin-dependent gene silencing on cell cycle exit.

\author{
Methods \\ Fly stocks and genetics \\ Disruption of $G 0$ in the posterior wing \\ $w / y$, w, hs-FLP; en-GAL4, UAS-GFP/UAS-E2F1, UAS- \\ DP; tub-gal80TS/+ \\ $w / y$, w, hs-FLP; en-GAL4, UAS-GFP/UAS-CycD, UAS- \\ Cdk4; tub-gal80TS/UAS-E2F1, UAS-DP \\ $w / y$, w, hs-FLP; en-GAL4, UAS-GFP/+; tub-gal80TS/ \\ $U A S-C y c E, U A S-C d k 2$ \\ $w / y$, w, hs-FLP; en-GAL4, UAS-GFP/UAS-CycD, UAS- \\ Cdk4; tub-gal80TS/+
}

\section{Disruption of $\mathrm{GO}$ in clones}

$w / y, w, h s-F L P ; t u b>C D 2>G A L 4, U A S-G F P / U A S-C y c D$, UAS-Cdk4; tub-gal8OTS/UAS-E2F1, UAS-DP

\section{Disruption of H3K27me3}

$w / y$, v; en-GAL4, UAS-GFP/+; tub-gal80TS/UAS-E $(z)^{R N A i}$

(Bloomington 33659)

\section{Disruption of HP1}

$w / y, \quad v ; \quad$ en-GAL4, UAS-GFP/+; tub-gal80TS/UAS$\mathrm{Su}\left(\right.$ var) $205^{R N A i}$ (Bloomington 33400)

\section{Disruption of HP1 with Y10C}

w/w, Y10C; en-Gal4, UAS-RFP/+; +/UAS-Su(var)205 $5^{R N A i}$ (Bloomington 33400)

All the crosses containing gal $80^{\mathrm{TS}}$ were maintained in $18{ }^{\circ} \mathrm{C}$ to suppress Gal4 in early development. To disrupt $G_{0}$ with cell cycle regulators, white prepupae were collected and shifted to $28{ }^{\circ} \mathrm{C}$ to indicated time points. For $E(z)$ knockdown experiments, L3 larva were shifted from 18 to $28{ }^{\circ} \mathrm{C}$ to induce $E(z)$ RNAi. For $H P 1$ knockdown, crosses were kept in $28{ }^{\circ} \mathrm{C}$ after egg laying (AEL). For clonal expression of cell cycle regulators, animals were heat-shocked in $37^{\circ} \mathrm{C}$ for 8 min during 48-72 h AEL and then kept in $18{ }^{\circ} \mathrm{C}$. White prepupae were collected and shifted to $28^{\circ} \mathrm{C}$ to indicated time points. All timings are adjusted according to the equivalent development at $25^{\circ} \mathrm{C}$ as described previously [18].

\section{Immunostaining}

Imaginal disks or pupal wings were dissected in $1 \times$ PBS and fixed in $4 \%$ paraformaldehyde $/ 1 \times$ PBS for $30 \mathrm{~min}$ utes. Samples were washed twice in $1 \times$ PBS, $0.1 \%$ Triton $\mathrm{X}, 10$ min each and incubated in PAT $(1 \times$ PBS, $0.1 \%$ Triton X-100 and 1\% BSA) for 10 min for larval tissues and $3 \times 20$ min for pupal tissues. Samples were then incubated with primary antibodies for $4 \mathrm{~h}$ or $4{ }^{\circ} \mathrm{C}$ overnight 
followed by three washes and secondary antibodies at room temperature for $4 \mathrm{~h}$ or $4{ }^{\circ} \mathrm{C}$ overnight. Primary antibodies used in this study include: Anti-phospho-Ser10 histone H3, 1:2000 rabbit (Millipore \#06-570) or mouse (Cell Signaling \#9706); Anti-GFP, 1:1000 chicken (Life Technologies A10262) or 1:1000 rabbit (Life Technologies A11122); Anti-pH2Av, 1:100 mouse (DSHB, UNC935.2.1); Anti-H3K27me3, 1:500 rabbit (Millipore \#07-449); Anti-HP1, 1:250 mouse (DSHB, C1A9); Anti-H2Av, 1:500 rabbit (Active Motif \#39715); Anti-H3, 1:500 mouse (Cell Signaling \#3638); Anti-H3ac, 1:500 rabbit (Millipore \#06-599); Anti-H3K4me3, 1:500 rabbit (Millipore \#07473); Anti-H3K9me3, 1:500 rabbit (Millipore \#07-523) or (Active Motif \#39161); Anti-H3K27ac, 1:500 rabbit (Abcam ab4729); Anti-H4ac, 1:500 rabbit (Millipore \#06866); Anti-H4K16ac, 1:500 rabbit (Millipore \#07-329); Anti-H4K20me3, 1:500 mouse (Abcam ab78517); AntiE2F, 1:500 guinea pig (kindly provided by Dr. Terry L. Orr-Weaver); Anti-Ubx, 1:250 mouse (DSHB, FP3.38); Anti-D1, 1:200 guinea pig (kindly provided by Dr. Yukiko Yamashita). DNA was labeled by $1 \mu \mathrm{g} / \mathrm{ml}$ DAPI in $1 \times$ PBS, 0.1\% Triton X for $10 \mathrm{~min}$. F-actin was stained using 1:100 rhodamine-phalloidin (Invitrogen; R415) in $1 \times$ PBS for $4 \mathrm{~h}$.

\section{Microscopy and image quantification}

Images were taken with a $100 \times$ oil objective on a Leica SP5 confocal with a system optimized z-section of $0.13 \mu \mathrm{m}$. Three-dimensional reconstructions were performed using the " $3 \mathrm{D}$ viewer" function in Leica LAS AF software. Images of whole pupal wings in Figs. 2 and 7 were obtained using a Leica DMI6000B epifluorescence system. All adjustments of brightness or contrast were applied to the entire image in Adobe Photoshop and performed equally with equal threshold values across control and experiment samples.

For integrated intensity quantifications, we used maximum projections of 12 continuous $\mathrm{z}$-sections of confocal images. We developed a toolkit in MATLAB (Release 2015b) that automatically segments nuclei and foci within nuclei and integrates the pixel intensities with the help of the Advocacy and Research Support, U. Michigan LSA-IT. To identify nuclei, images were smoothed using a circular averaging filter through the fspecial and imfilter function of MATLAB. Next, a watershed algorithm was applied to segment nuclei from the background, and nuclei were masked using local maxima with an h-maxima transform. Thresholds were manually set and checked for each image to accurately delineate nuclei. GFP positive versus negative was established using an intensity threshold for the GFP channel. Integrated intensities for all nuclei were exported to Excel. Segmentation and measurement of foci followed a similar process for foci within the defined nuclear regions. In brief, foci were segmented using a watershed algorithm and then further measured for pixel intensity and number, which was used for foci area and intensity measurements.

\section{Fluorescent in situ hybridization (FISH)}

Alexa-488 probes against the rDNA internal transcribed spacer (ITS) region and Cy3 probes against AACAC repetitive satellite sequences were kindly provided by $\mathrm{Dr}$. Yukiko Yamashita. For FISH, fixed tissues were treated with $2 \mathrm{mg} / \mathrm{ml}$ Rnase A in $1 \times$ PBS, $0.1 \%$ Triton $\mathrm{X}$ at $37{ }^{\circ} \mathrm{C}$ for $10 \mathrm{~min}$, and rinsed in $2 \times \mathrm{SSC} / 1 \mathrm{mM}$ EDTA/0.2\% Tween 20 . Then tissues were incubated in $2 \times \mathrm{SSC} / 1 \mathrm{mM}$ EDTA/0.2\% Tween 20 solution with increasing formamide concentration from 20,40 to $50 \%$ for $15 \mathrm{~min}$ to $30 \mathrm{~min}$. Finally, tissues were incubated in $100 \mu \mathrm{l}$ hybridization solution with $50 \mu \mathrm{l}$ formamide, $20 \mu \mathrm{l} 50 \%$ dextran sulfate, $20 \mu \mathrm{l} 2 \times \mathrm{SSC} / 1 \mathrm{mM}$ EDTA $/ 0.2 \%$ Tween 20 and $10 \mu \mathrm{l}$ of $10 \mu \mathrm{m}$ probe for $15 \mathrm{~min}$ at $91{ }^{\circ} \mathrm{C}$ and left at $37^{\circ} \mathrm{C}$ overnight. Quantification of size for rDNA loci area was carried out using our customized MATLAB toolkit. For the quantification of AACAC satellite to the chromocenter, we used a single $0.13-\mu \mathrm{m}$ z-section with the strongest FISH signal and measured the relative distance of the center of the FISH signal to the brightest Dapistained region and corrected for the total nuclear radius using the Leica LAS AF software.

\section{Flow cytometry}

FACS was performed on dissociated wings to measure DNA content on an Attune Cytometer (Life Technologies) as described [21].

\section{RNA interference}

Kc167 cells were kindly provided by Dr. K. Cadigan and cultured as described [22]. For RNA interference, cells were placed with concentration of $1 \mathrm{million} / \mathrm{ml}$ and starved in serum-free medium with $10 \mu \mathrm{g} / \mathrm{ml}$ doublestrand RNA (dsRNA) for $4-6 \mathrm{~h}$, then $10 \%$ serum medium was added to the culture, and cells were collected for staining 3 days after serum medium addition. dsRNA was synthesized with T7 Megascript Kit (Ambion). T7 primers used in this study:

\footnotetext{
T7-Wee-fwd, TAATACGACTCACTATAGGGATGAC TTTGACAAGGACAC;

T7-Wee-rev, TAATACGACTCACTATAGGATCTAG TCGATTGACGCATT;

T7-Myt1-fwd, TAATACGACTCACTATAGGAATTG CACGACGACAAACAC; T7-Myt1-rev, TAATACGACTCACTATAGGTGTCC AGATGGATGAGATTC;
} 
T7-Myt1-fwd2, TAATACGACTCACTATAGGACAA CAATCTGAACCGAAGC; T7-Myt1-rev2, TAATACGACTCACTATAGGTGGA GCCATATACCTCGAAT;

T7-GFP-fwd, TAATACGACTCACTATAGGCATGT GGTCTCTCTTTTCGT

T7-GFP-rev, TAATACGACTCACTATAGGGGGCAC AAATTTTCTGTCAG

T7-CycB-fwd TAATACGACTCACTATAGGGGCGT TTTTGCGTTCGAATT

T7-CycB-rev, TAATACGACTCACTATAGGCAATT GCAAGTACGTGCGTT.

\section{Western blots}

Western blots were performed on staged fly wings using Bio-Rad TGX precast 4-20\% gels and high-sensitivity ECL reagents (Thermo) to detect HRP-conjugated secondary antibodies [23]. Mouse anti- $\alpha$-tubulin (1:1000, DSHB, AA4.3) was used as a loading control. Blot signals were detected and quantified with FluorChem $M$ digital system from ProteinSimple.

\section{Results \\ Heterochromatin clusters as proliferation slows and cells differentiate}

The impact of the cell cycle on heterochromatin clustering during cellular differentiation has not been resolved. Specifically, how the transition from a proliferative to a postmitotic state impacts global chromatin organization in Drosophila is unclear. To examine this, we immunostained for various chromatin marks and chromatin binding proteins in wild-type Drosophila wings at three stages with distinct proliferation parameters. We examined quickly proliferating second instar larval (L2) wings, slowly proliferative wandering third instar larva (L3) and postmitotic $28 \mathrm{~h}$ pupal wings (Fig. 1A). Cells of the L2 wing region examined have a cell doubling time (CDT) of about $10 \mathrm{~h}$, while cells of the same region in L3 wings have a longer CDT of $15 \mathrm{~h}$. By $28 \mathrm{~h}$ after puparium formation (APF) during metamorphosis, cells of the wing blade have entered G0 and are permanently postmitotic $[18,24,25]$. We examined the histone modification H3K27me3 associated with facultative heterochromatin, H3K9me3, HP1 and the AT-rich repetitive sequence binding protein D1 associated with constitutive heterochromatin and the euchromatin-associated modification H3K4me3 (Fig. 1A). The immunofluorescence (IF) signals for H3K27me3, H3K9me3 and D1 were weakest at the L2 stage, but increased at the L3 and pupal stages, and clustered into larger and more intense, distinct foci in the slower cycling tissues (Fig. 1A). In Drosophila cells, the chromocenter, containing constitutive heterochromatin such as clustered centromeres, can be easily visualized as a DAPI-bright region within the nucleus [26]. We confirmed the co-localization of the chromocenter with D1 staining, which binds centromeric satellite repeats, and also co-localized with the centromeric histone CenpA (not shown) [27]. H3K9Me3 and HP1 label heterochromatin foci partially overlapping and adjacent to the DAPI-bright region [28]. H3K27Me3 labels distinct foci throughout the nucleus associated with facultative heterochromatin and represents Polycomb repressive complex 2 (PRC2) binding and formation of Polycomb group (PcG) clusters or foci [29-31]. By contrast, H3K4Me3 broadly localizes throughout the chromatin, does not form distinct foci and is excluded from the centromeric and pericentromeric regions (Fig. 1A).

To automatically detect and measure heterochromatin foci parameters such as intensity and number for a large number of nuclei, we developed a custom MATLAB App (described in supplemental methods) that uses DAPI staining to mask individual nuclei followed by foci segmentation and measurement. We measured clustering of heterochromatin foci as a function of the integrated intensity for each focus (the sum of intensities for all pixels in a focus) [17, 31]. This automated approach allowed us to examine the distribution of heterochromatin foci at a single cell level, across hundreds to thousands of nuclei, sampled from multiple wings for each experiment in an unbiased manner. We found that heterochromatin

\footnotetext{
(See figure on next page.)

Fig. 1 Heterochromatin clustering increases as the cell cycle slows and cells differentiate. A Wings of the indicated developmental stages were immunostained for the indicated chromatin modifications and chromatin binding proteins. B As the cell cycle slows down and cells differentiate, the distribution of heterochromatin-associated foci shifts toward larger, brighter foci indicating increased clustering. Coalescence is quantified as the total intensity of individual focus within 129-448 nuclei at each developmental stage. C, D Kc cells treated with dsRNA against GFP, wee/myt and $c y c B$ were immunostained for the indicated chromatin modifications and fluorescence intensity was quantified. $\mathbf{E}, \mathbf{F}$ Fluorescent in situ hybridization (FISH) against the rDNA ITS region was performed on wings of the indicated stages. rDNA foci coalesce and condense in postmitotic cells. G, H FISH against the AACAC pericentromeric satellite repeats was performed on wings of the indicated stages and the distance to the center of the DAPI-bright chromocenter was measured. The distance decreases in postmitotic cells indicating increased condensation of heterochromatin. I A box plot of the RNA $\log _{2}$-fold changes compared to proliferative L3 for each time point is shown. J A line plot of average FAIREseg signal across all accessible chromatin for the indicated stages is shown. The accessibility of regulatory elements is similar in cycling and postmitotic wings. Scale bars $=2 \mu \mathrm{m}$. $P$ values were determined by an unpaired $t$ test ${ }^{*}<0.05 ;^{* *}<0.01 ;{ }^{* * *}<0.001 ;{ }^{* * * *}<0.0001$
} 
A
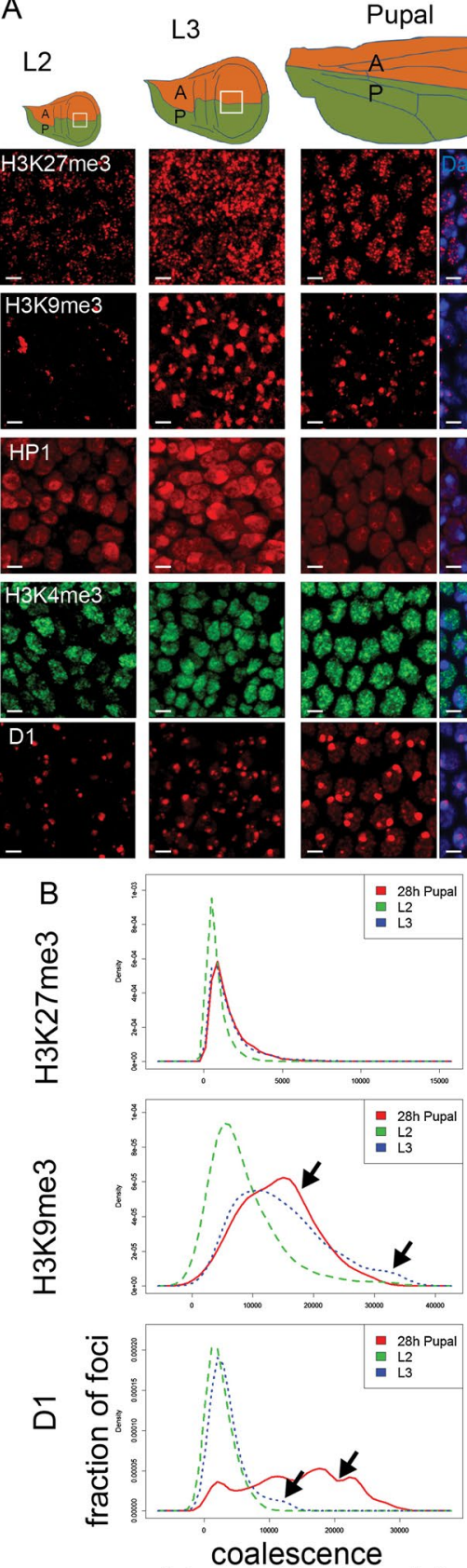

(integrated foci intensity)

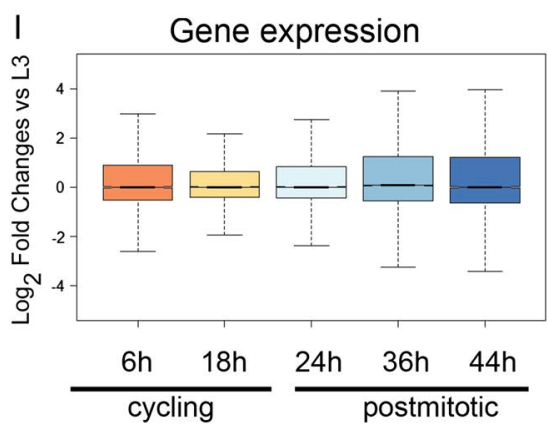

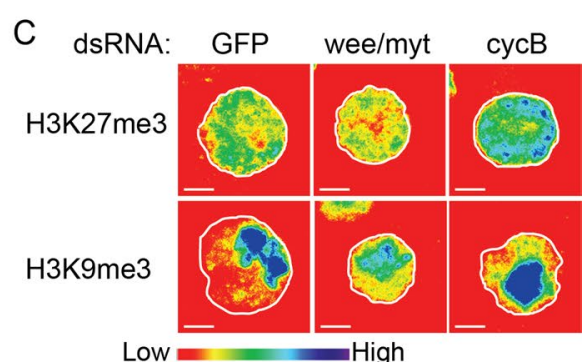

D

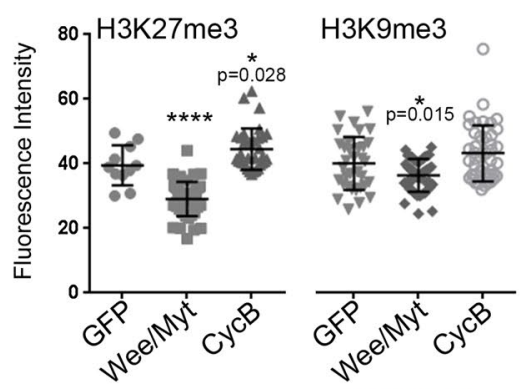

E
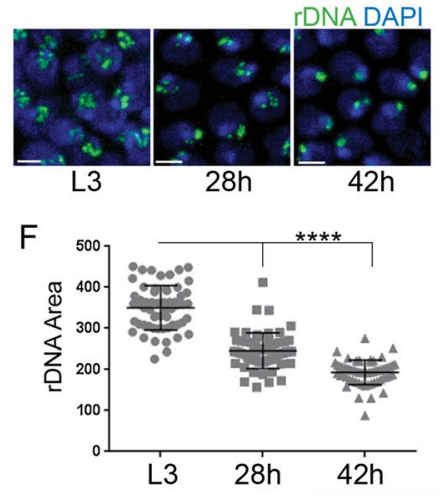

G
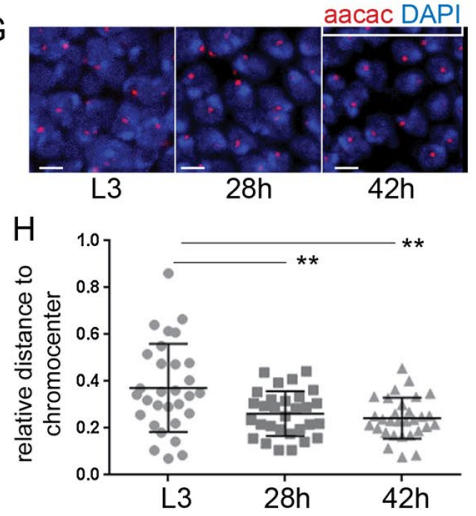

J Chromatin accessibility

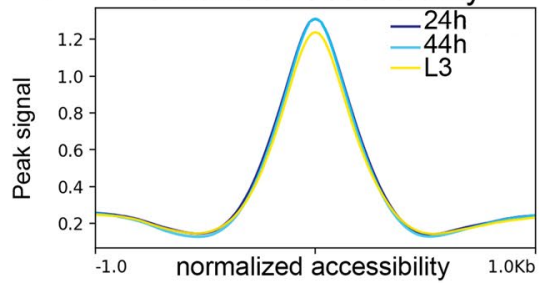



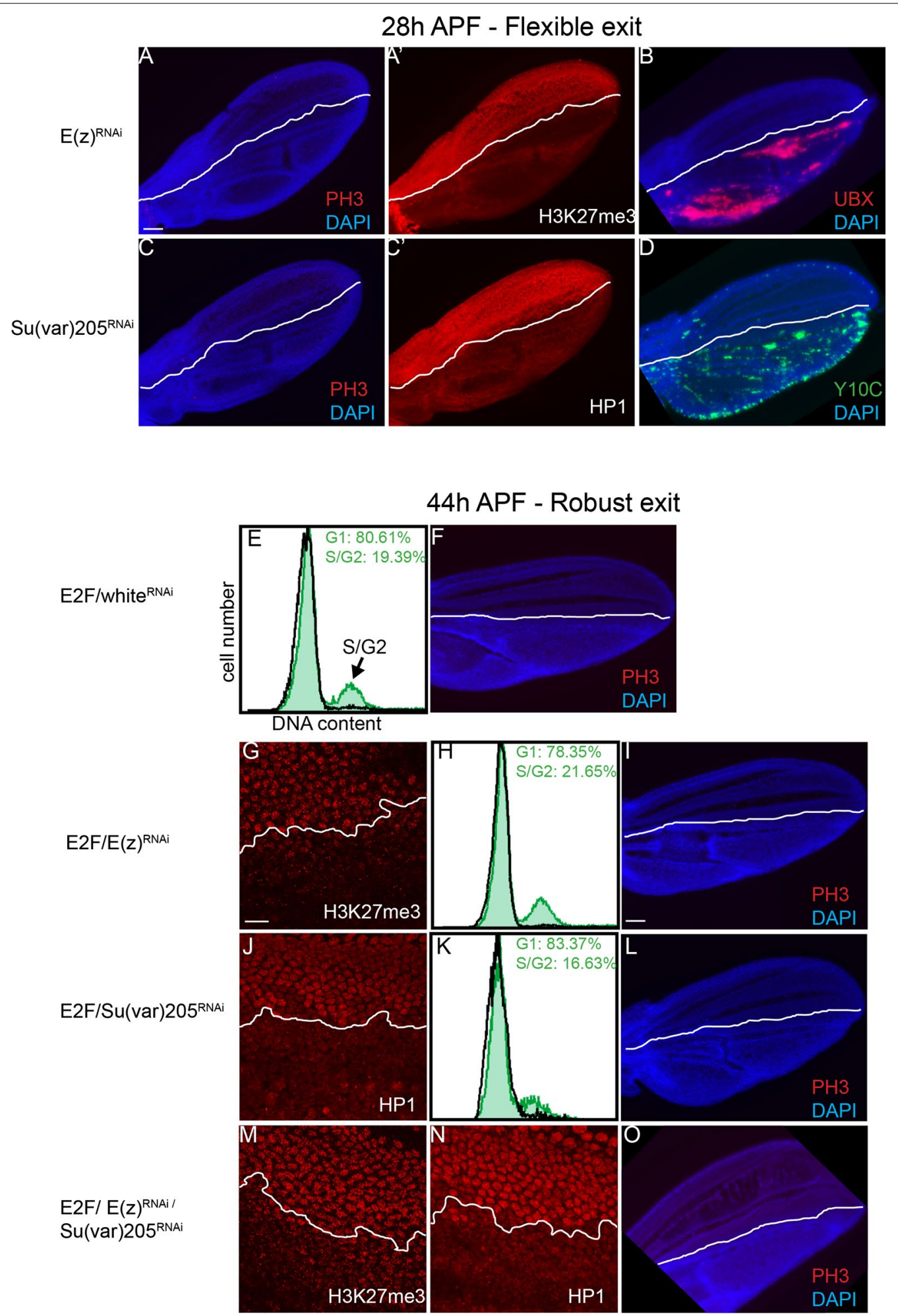
(See figure on previous page.)

Fig. 2 Heterochromatin-dependent gene silencing is not required for cell cycle exit. A, B RNAi to $E(z)$ was expressed in the posterior wing from the L3 stage until the indicated time points in metamorphosis. Postmitotic wings at $26-28 \mathrm{~h}$ were examined for mitoses as indicated by phosphoSer10-histone H3, PH3 (A), H3K27me3 ( $\mathbf{A}^{\prime}$ ) and de-repression of Ubx (B). C RNAi to Su(var)205 (the gene encoding HP1) was overexpressed in the posterior wing, and postmitotic tissues were immunostained for PH3 and HP1 ( $\left.\mathbf{C}^{\prime}\right)$. These conditions led to loss of HP1 and disrupted heterochromatin-mediated silencing of the $\mathrm{Y} 10 \mathrm{C}$ reporter (D). Control RNAi (to the white gene), $E(z)$ and/or Su(var) 205 was expressed in the posterior wing in combination with E2F from the start of metamorphosis. Postmitotic wings at 42-44 h were dissected and examined for H3K27me3 (G, M), HP1 (J, $\mathbf{N})$ and PH3 $(\mathbf{F}, \mathbf{I}, \mathbf{L}, \mathbf{O})$. E, $\mathbf{H}, \mathbf{K}$ Flow cytometry was also performed to measure cells that enter $\mathbf{S}$ and $\mathrm{G} 2$ phases. Green trace indicates cells from the posterior wing expressing the indicated transgenes. Black trace: control non-expressing anterior wing cells. Reduced heterochromatin gene silencing does not compromise $\mathrm{G} 0$ even in the presence of high E2F activity. Scale bars $=50 \mu \mathrm{m} \mathbf{A}-\mathbf{D}, \mathbf{F}, \mathbf{I}, \mathbf{L}$ and $\mathbf{O} ; 10 \mu \mathrm{m} \mathbf{G}, \mathbf{J}, \mathbf{M}$ and $\mathbf{N}$

clustering increased as the cell cycle slowed and stopped during L3 and pupal stages (Fig. 1B). We noted a dramatic increase in $\mathrm{H} 3 \mathrm{~K} 9 \mathrm{Me} 3$ and $\mathrm{HP} 1$ staining at the L3 stage, which may reflect a developmentally controlled stage-specific increase in this modification/reader pair.

To distinguish whether an increase in heterochromatin clustering is due to the changes in the cell cycle, we turned to Drosophila cell culture. In Drosophila Kc cells, the overall cell doubling time is controlled by the negative and positive regulators of the G2/M transition Wee/Myt and Cyclin B, respectively [22]. We sped up the cell cycle by reducing Wee/Myt1 activity via RNAi or slowed the cell cycle using RNAi to cyclin B. Slowing the cell cycle increased the clustering and intensity of H3K27Me3 and H3K9Me3 compared to controls exposed to RNAi to GFP (Fig. 1C, D).

The increased clustering of heterochromatin could be due to chromatin condensation and compaction. To examine chromatin condensation, we performed fluorescent in situ hybridization (FISH) using probes against the internal transcribed spacer region between the $18 \mathrm{~S}$ RNA and $28 \mathrm{~S}$ rDNA loci, which are tandemly repeated on the $\mathrm{X}$, and measured the total rDNA area before and after cell cycle exit in the wing [32, 33]. In proliferating L3 wings, the rDNA is extended. The rDNA becomes more compact as cells enter G0 at 24-28 h APF and condenses further as G0 is maintained at $42 \mathrm{~h} \mathrm{APF} \mathrm{(Fig.} \mathrm{1E,}$ F). The changes in the rDNA locus suggest chromatin condensation increases in prolonged G0. To verify that compaction is not specific to the rDNA locus on the $\mathrm{X}$, we also performed FISH to the pericentromeric satellite repeat AACAC on chromosome II and measured the distance of the signal to the chromocenter (Fig. 1G, H). The distance of the pericentromeric heterochromatin to the chromocenter also decreased suggesting that heterochromatin condensation, coalescence and compaction occur throughout the nucleus after cell cycle exit.

An increase in chromatin clustering could be correlated with a global reduction in gene expression when cells become postmitotic [34]. To test whether global gene expression is reduced in postmitotic wings, we examined an RNAseq time course of gene expression from proliferating to postmitotic stages [22]. We found the global gene expression levels to be similar in proliferating and postmitotic tissues (Fig. 1I); however, since RNAseq reveals steady-state mRNA levels, changes in RNA Pol II could still occur. Transcriptional shutoff upon quiescence in yeast is associated with a repressive chromatin structure and reduced chromatin accessibility [34]. Therefore, we also compared the global changes in chromatin accessibility between proliferating and postmitotic wings through Formaldehyde-Assisted Identification of Regulatory Elements (FAIRE)-seq [35] (Fig. 1J). Consistent with the global gene expression profile, we found no obvious changes in the average level of chromatin accessibility in cycling versus postmitotic tissue. This suggests that clustering of heterochromatin as cells exit the cell cycle does not cause global changes in genome accessibility or steady-state mRNA levels during differentiation and cell cycle exit.

\section{Compromising heterochromatin-dependent gene silencing does not disrupt cell cycle exit}

We have shown that heterochromatin clustering increases with entry into G0. Heterochromatin clustering is associated with increased target gene silencing [31] and has been suggested to repress cell cycle gene expression to facilitate cell cycle exit in mammalian muscle and neurons [36-38]. To test whether heterochromatin-dependent gene silencing promotes cell cycle exit in Drosophila wings, we compromised the H3K27me3 methyltransferase $E(z)$ and/or the H3K9Me3 binding protein HP1. As $E(z)$ and HP1 perform many functions during development, we turned to an inducible system with RNAi to alter gene function after embryogenesis. We used the engrailed-Gal4 driver with a temperature sensitive Gal80 (en-Gal4/Gal80 ${ }^{\mathrm{TS}}$ ) to turn on UAS-driven expression of dsRNAs to $E(z)$ and $H P 1$ in the posterior wing from the early L1 and L3 stages, respectively. We then dissected wings at 24-28 h APF and stained for the mitotic marker phosphorylated phospho-Ser-10 histone $\mathrm{H} 3$ (PH3) to determine whether cells in the posterior wing delayed or bypassed cell cycle exit. We saw no effect of $E(z)$ or $H P 1$ reduction on cell cycle exit despite 
a clear loss of H3K27Me3 and HP1 in the posterior wing (Fig. 2A-C). We further confirmed that our knockdowns effectively compromised heterochromatin-dependent gene silencing in the wing, by examining de-repression of the Polycomb target Ultrabithorax (UBX) and the HP1silenced Y10C GFP reporter (Fig. 2B, D). Recent work has suggested Polycomb (Pc) can repress certain targets independent of $E(z)$ [29]. We therefore also directly inhibited $P c$ by RNAi, but observed no effect on cell cycle exit despite de-repression of UBX in the wing (Additional file 1: Fig. S2).

Compromising heterochromatin-dependent gene silencing does not disrupt or delay cell cycle exit on its own, but we wondered whether it may sensitize cells to other perturbations that compromise cell cycle exit. We have previously shown that activation of various cell cycle regulators, including the cell cycle transcription factor complex E2F/DP (hereafter referred to as E2F), can cause 1-2 extra cell cycles in the pupa wing between 24 and $36 \mathrm{~h}$ APF followed by a delayed entry into G0 at 36 APF (Additional file 2: Fig. S3). We refer to the 24-36 h APF period as flexible cell cycle exit or "flexible G0" which is followed by a more difficult to disrupt "robust G0" after $36 \mathrm{~h}$. We co-expressed E2F with RNAi to $E(z)$ and/or HP1 to examine whether loss of heterochromatindependent gene silencing can further delay cell cycle exit in the presence of high E2F activity. However, inhibition of $E(z), H P 1$ or $E(z)+H P 1$ together did not further compromise cell cycle exit in the presence of high E2F activity (Fig. 2G-O). Altogether our results demonstrate that compromising heterochromatin-dependent gene silencing does not disrupt cell cycle exit in the Drosophila wing.

\section{Delaying cell cycle exit disrupts heterochromatin clustering and chromosome compaction}

Constitutive and facultative heterochromatin clusters in postmitotic wings. To examine whether compromising cell cycle exit affects clustering, we used the system described above to express E2F in the posterior pupal wing to drive 1-2 extra cell cycles and delay exit from 24 to $36 \mathrm{~h}$ APF. We immunostained for the heterochromatin-associated histone modifications H3K27me3, H3K9me3 and H4K20me3 at 26-28 h APF, a time point when E2F induces abundant mitoses in the posterior wing (Additional file 2: Fig. S3). We compared the clustering of the chromatin marks in the unperturbed anterior to the posterior wing. When cell cycle exit is delayed, all three modifications appear more diffuse throughout the nucleus and heterochromatin clustering is disrupted (Fig. 3A-M). To determine whether E2F altered the total abundance of the modified histones, we performed semiquantitative western blots on 28 -h pupal wings. With E2F expression, total levels of $\mathrm{H} 3$ were increased, consistent with additional S-phases leading to replication-coupled canonical histone production $[39,40]$. However, the ratio of modified $\mathrm{H} 3$ to total $\mathrm{H} 3$ was relatively unchanged or even slightly increased when cell cycle exit was delayed (Additional file 3: Fig. S1). This may be because E2F activity also increases the expression of several PRC2 components $(E(z), e s c, S u(z) 12)$ and $S u(v a r) 3-9)$ as well as several other histone modifying enzymes (Additional file 4: Table S1), a feature conserved with mammalian E2Fs [41]. Thus, delaying cell cycle exit increases new histone production, but the histone modification rate is maintained by a coordinated increase in the expression of the modifying enzymes.

\section{Delaying cell cycle exit disrupts the localization of heterochromatin-associated proteins}

To determine whether delaying cell cycle exit also affected the localization of proteins associated with heterochromatin, we examined HP1, D1 and Polycomb using a Pc-GFP fusion protein [17]. We observed a more diffuse localization and a reduction in the clustering of these heterochromatin-associated proteins when cell cycle exit was compromised (Fig. 4A-M). This was also accompanied by a reduction in heterochromatin condensation, as assessed by the distance of the AACAC satellite to the chromocenter (Fig. 4N).

The accumulation of PRC1 components such as Pc into large foci or Pc bodies is important for target gene repression [17, 31]. Since E2F expression disrupts Pc clustering we examined whether increased E2F activity can disrupt the repression of Pc target genes [42-44]. We selected 12 high-confidence Pc target genes predicted not to be direct E2F targets based upon published genome-wide E2F complex binding in Drosophila [45]. We examined their expression upon E2F activation in pupal wings at 24 and $36 \mathrm{~h}$ APF using our previously published array data

(See figure on next page.)

Fig. 3 Heterochromatin clustering is disrupted when GO is compromised. E2F was co-expressed with GFP in the posterior wing (boundary indicated by a white line) from the start of metamorphosis ( $0 \mathrm{~h} \mathrm{APF)} \mathrm{to} \mathrm{delay} \mathrm{cell} \mathrm{cycle} \mathrm{exit.} \mathrm{At} 26-28 \mathrm{~h}$ wings were dissected and immunostained for the indicated chromatin modifications and DAPI to label nuclei $(\mathbf{A}-\mathbf{I})$. J-M Fluorescence signal were measured for 485-848 nuclei for each chromatin modification. The distribution of overall fluorescence intensity $(\mathbf{J})$, foci number per nucleus section $(\mathbf{K})$ and individual focus intensity $(\mathbf{L}, \mathbf{M})$ all indicate that delaying cell cycle exit disrupts heterochromatin clustering in wing cell nuclei. Scale bars $=10 \mu \mathrm{m}$ in $\mathbf{A}-\mathbf{I}$ except for anterior (A) and posterior (P) zoomed images where the bar $=2 \mu \mathrm{m}$ (e.g., $\mathrm{B}_{\mathrm{A},}, \mathrm{B}_{\mathrm{p}}$ ). $P$ values were determined by an unpaired $t$ test. ${ }^{*}<0.05 ;^{* *}<0.01 ;{ }^{* * *}<0.001 ;{ }^{* * * *}<0.0001$ 

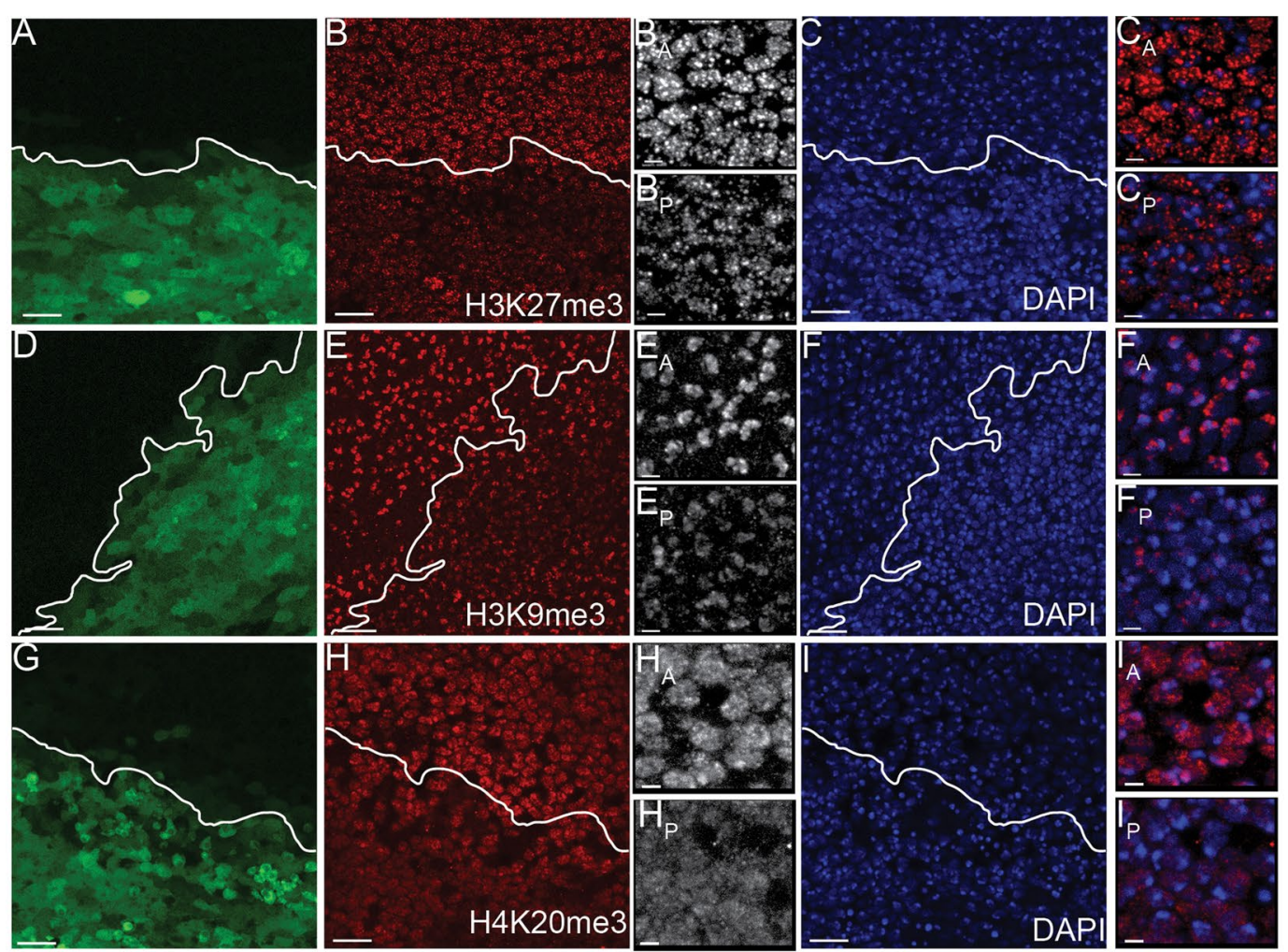

$$
\mathrm{J}
$$

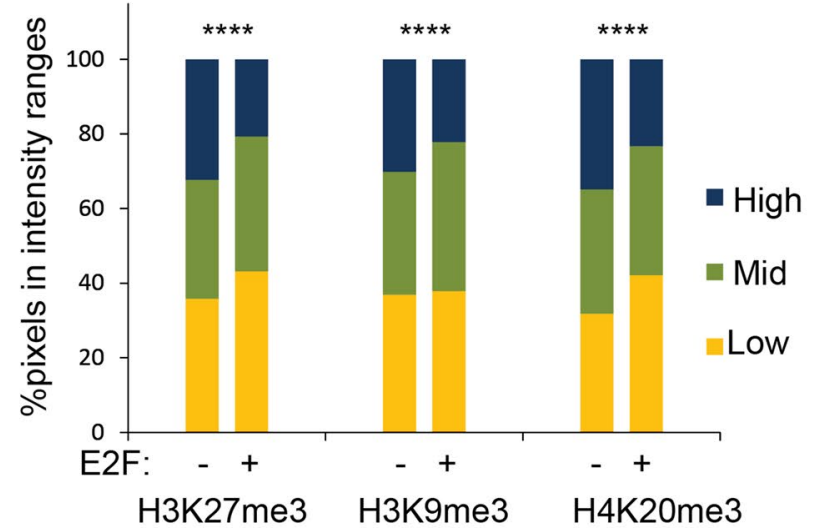

$\mathrm{K}$
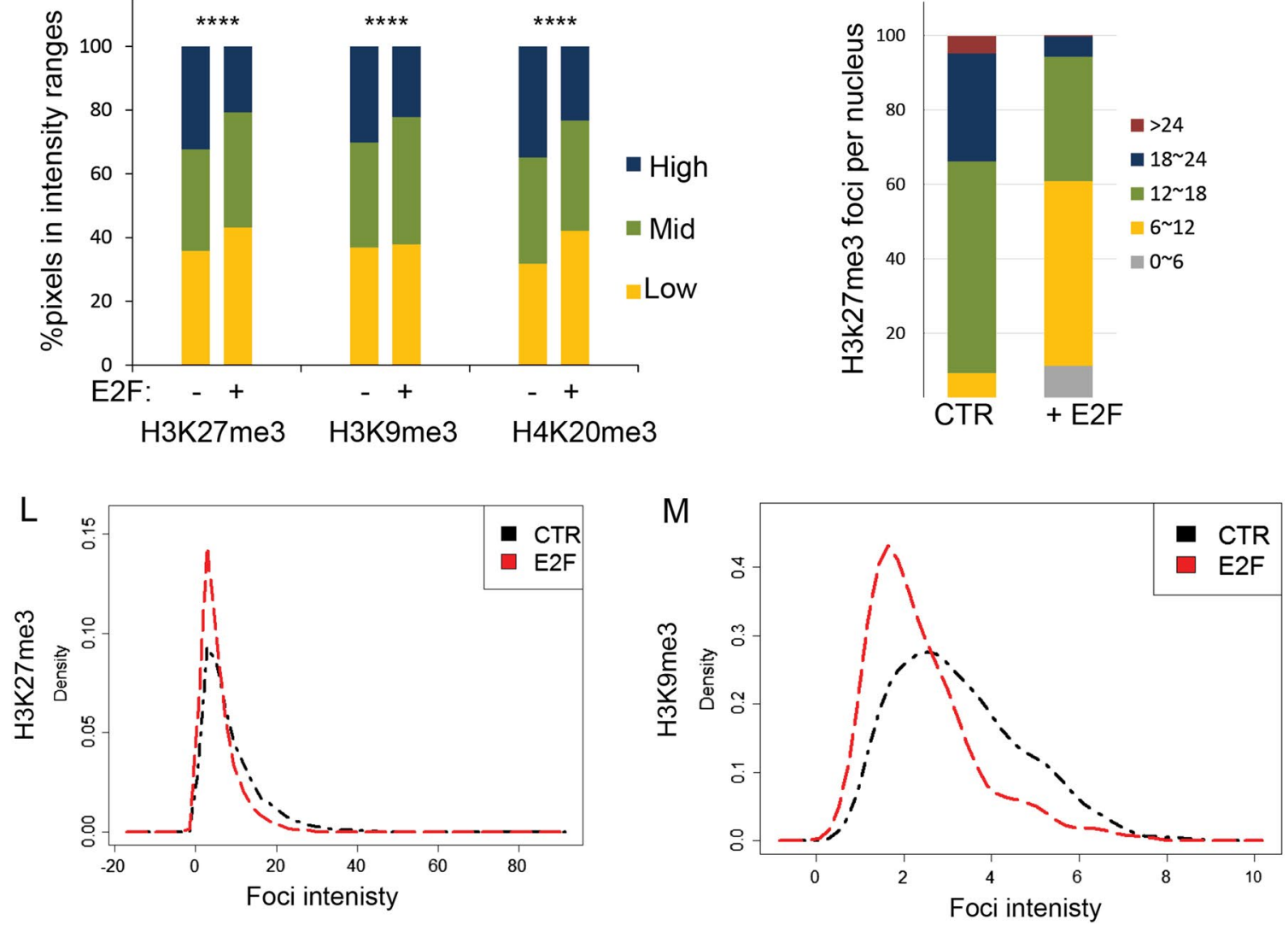

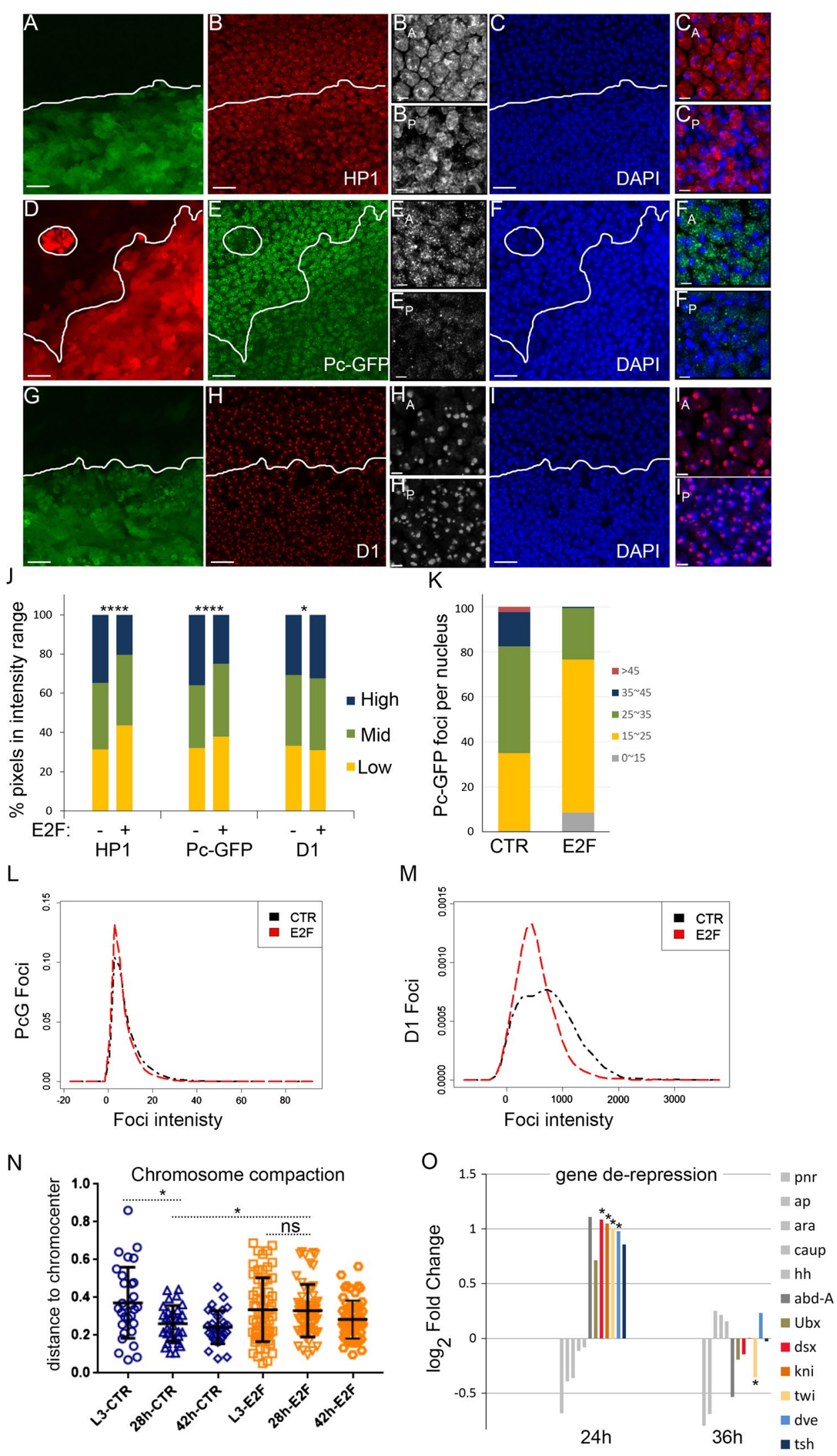
(See figure on previous page.)

Fig. 4 Compromising G0 disrupts D1, HP1 and Polycomb body clustering and leads to partial de-repression of select PcG targets. E2F was coexpressed with GFP or RFP in the posterior wing to delay cell cycle exit. At 26-28 h wings were dissected and immunostained for the indicated heterochromatin binding proteins and DAPI to label nuclei $(\mathbf{A}-\mathbf{I})$. J Overall fluorescence intensities were measured for 319-1270 nuclei for each chromatin modification. The distribution of individual focus intensity $(\mathbf{L}, \mathbf{M})$, foci number per nucleus section $(\mathbf{K})$ all indicate that delaying cell cycle exit disrupts heterochromatin clustering and formation of large Polycomb bodies in wing cell nuclei. $\mathbf{N}$ Chromosome compaction was measured using the distance of the AACAC repeats to the chromocenter. When cell cycle exit is delayed, chromosome compaction is also compromised. For J, N, $P$ values were determined by an unpaired $t$ test. ${ }^{*}<0.05 ;{ }^{* *}<0.01 ;{ }^{* * *}<0.001 ;{ }^{* * * *}<0.0001$. O Microarray analysis revealed specific PcG target genes that become temporarily de-repressed in wings expressing E2F at $24 \mathrm{~h}$ when cell cycle exit is delayed. $P$ values were determined by ANOVA ${ }^{*}<0.05$. Scale bars $=10 \mu \mathrm{m}$ in $\mathbf{A}-\mathbf{I}$ except for anterior $(A)$ and posterior $(P)$ zoomed images where the bar $=2 \mu m\left(e . g ., B_{A^{\prime}}, B_{P}\right)$

[46]. We found four Pc targets, $d s x, k n i$, twi and $d v e$ to be reproducibly de-repressed $1.97-2.12$-fold specifically at $24 \mathrm{~h} \mathrm{APF}$, during the window of time that cell cycle exit is delayed. This suggests that delaying cell cycle exit can partially compromise Pc-dependent gene silencing. E2F activity similarly impacts heterochromatin-dependent gene silencing at the pericentromeric heterochromatin, with the loss of $e 2 f 1$ increasing gene silencing by position effect variegation and an increase in E2F activity derepressing variegated gene expression [47].

In our experiments to delay cell cycle exit, E2F is overexpressed for $28 \mathrm{~h}$, which includes the final 1-2 normal cell cycles in the pupa wing as well as 1-2 extra cell cycles based upon lineage tracing $[18,46]$. We therefore asked whether expression of E2F within only the final cell cycle during terminal differentiation is adequate to disrupt heterochromatin clustering. We used temperature shifts to limit the expression of E2F to a $12 \mathrm{~h}$ window within the final cell cycle in the pupa and observed a similar disruption of heterochromatin clustering (Additional file 5: Fig. S4). We also observed similar effects on heterochromatin clustering when cell cycle exit was delayed by expression of other cell cycle regulators such as CycE/Cdk2 or $\mathrm{CycD} / \mathrm{Cdk} 4$ (Additional file 6: Fig. S5). This demonstrates that heterochromatin clustering in differentiating cells can be disrupted by a single extra cell cycle and that this effect is not specific to E2F overexpression.

\section{Histone modifications associated with de-condensation are upregulated upon $\mathrm{GO}$ disruption}

Compromising G0 leads to the disruption of heterochromatin clustering and chromatin condensation (Fig. 4). H3K27ac and H4K16ac are associated with open chromatin such as active enhancers and origins [48-51], and H4K16ac can suppress the formation of higherorder chromatin structure [52]. We therefore examined whether these histone modifications were affected by delaying cell cycle exit with E2F overexpression. Indeed, during the delay of cell cycle exit, we observed dramatic increase in the levels of these two histone marks throughout the nucleus (Fig. 5A-D). However, other histone modifications associated with active chromatin were not affected, such as $\mathrm{H} 3 \mathrm{~K} 4 \mathrm{me} 3$, pan $\mathrm{H} 3$ and $\mathrm{H} 4$ acetylation (Fig. 5E-J). Thus, an increase of H3K27ac and H4K16ac could contribute to the compromised chromatin condensation and disruption of heterochromatin clustering observed when cell cycle exit is delayed.

\section{Heterochromatin clustering is restored when cells enter a robust G0 state}

Delaying cell cycle exit disrupts heterochromatin clustering; however, this is reversible. When we examined wings at $42-46 \mathrm{~h}$, a time point when cells enter a robust G0 state refractory to E2F activation, heterochromatin clustering is either partially or completely restored (Fig. 6). Interestingly, levels of H3K27me3 and HP1 became higher in robust G0 after cell cycle exit is delayed (Fig. 6A, D). This could be due to the E2F-dependent upregulation of $E(z)$ and $S u(v a r) 3-9$, which may indicate an expansion of heterochromatin in differentiating cells that enter a robust G0. Consistent with this idea we also observe an increase in the $\mathrm{H} 2 \mathrm{~A}$ variant $\mathrm{H} 2 \mathrm{Av}$ in E2F-expressing cells in robust G0 (Fig. 6F) and an upregulation of several components of the NuA4 complex responsible for incorporation of $\mathrm{H} 2 \mathrm{Av}$ (Additional file 4: Table S1). Heterochromatin expansion is associated with senescence, suggesting delaying cell cycle exit with E2F overexpression could induce oncogenic stress or senescence-like features [53, 54]. Consistent with this, ectopic E2F in the wing induced multiple genes associated with senescence in mammals during robust G0 (Additional file 7: Table S2) and led to a widespread increase in phosphorylated $\mathrm{H} 2 \mathrm{Av}$, a hallmark of E2F-induced replication stress and DNA damage in Drosophila (Fig. 6E) [55].

\section{Heterochromatin clustering during terminal differentiation is a consequence of cell cycle exit, rather than differentiation}

Heterochromatin clustering becomes restored at the robust G0 phase in the wing as terminal differentiation proceeds. But whether differentiation or cell cycle arrest restores the heterochromatin clustering remains unclear. We previously demonstrated that the robust G0 state in the wing can be bypassed by co-expression 


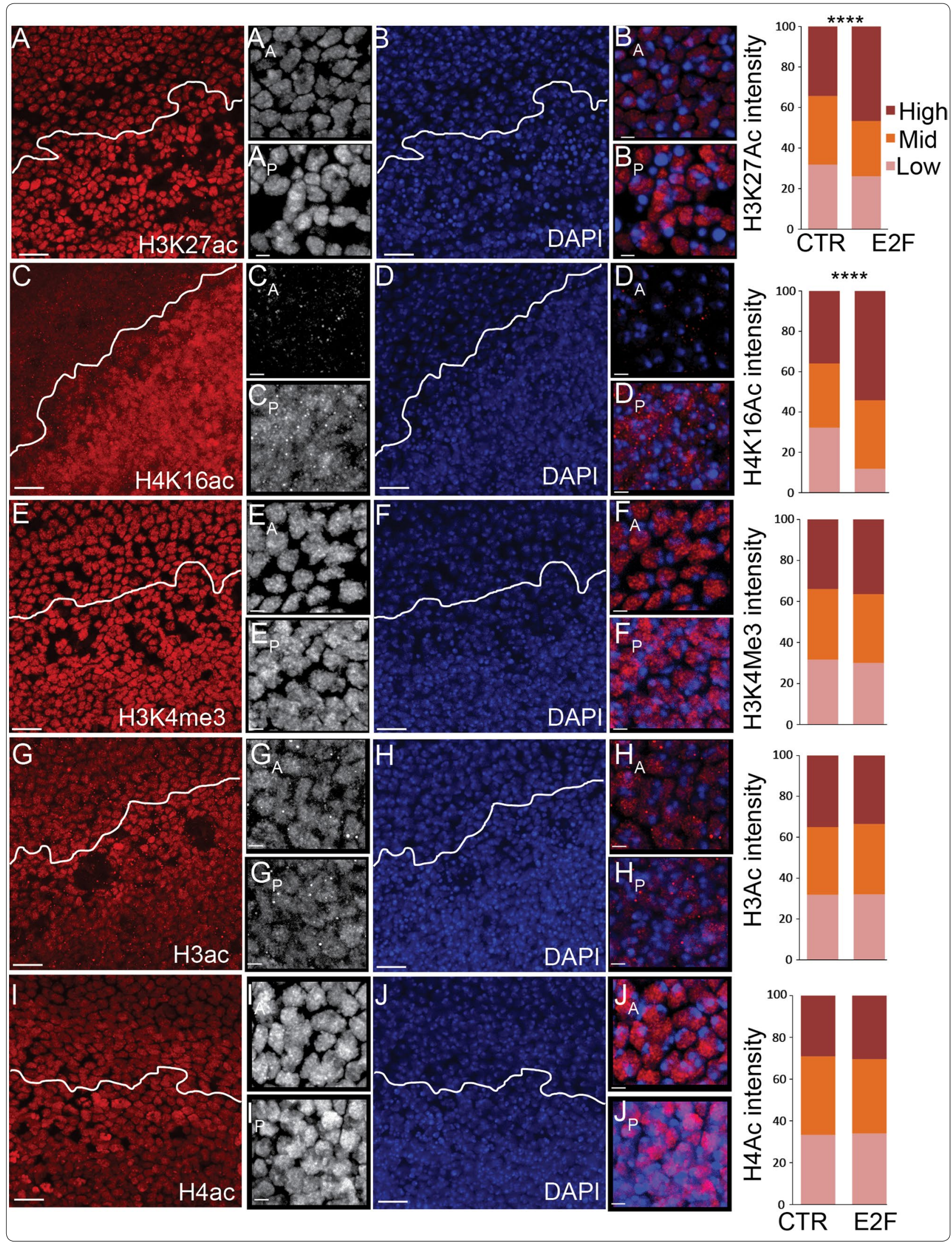


(See figure on previous page.)

Fig. 5 Specific histone modifications associated with gene activation are increased when flexible $\mathrm{G} 0$ is compromised. E2F was expressed in the posterior wing to delay cell cycle exit. At 26-28 h wings were dissected and immunostained for the indicated histone modifications and DAPI to label nuclei $(\mathbf{A}-\mathbf{J})$. The anterior-posterior boundary is indicated by a white line. The distribution of staining intensity in 217-1312 nuclei, binned into three ranges, is shown at right. Compromising flexible G0 specifically increases H3K27ac and H4K16ac. $P$ values were determined by an unpaired $t$ test; $^{* * * *}<0.0001$. Scale bars $=10 \mu \mathrm{m}$ in $\mathbf{A}-\mathbf{J}$ except for anterior $(\mathrm{A})$ and posterior $(\mathrm{P})$ zoomed images where the bar $=2 \mu \mathrm{m}\left(\mathrm{e} . \mathrm{g} ., \mathrm{B}_{\mathrm{A}}, \mathrm{B}_{\mathrm{P}}\right.$ )

of E2F + CycD/Cdk4 [18]. Under these conditions cells in the wing continue cycling past $48 \mathrm{~h} \mathrm{APF}$, yet physical hallmarks of wing terminal differentiation such as cuticle secretion and wing hair formation proceed after $36 \mathrm{~h}$ and adult wings form. This condition effectively uncouples cell cycle exit from terminal differentiation in the wing, with actively dividing cells forming actin-rich wing hairs and developing adult cuticle (Fig. 7A-E). We took advantage of this dividing-yet-differentiated context to ask whether heterochromatin clustering requires cell cycle exit. We immunostained $42 \mathrm{~h}$ wings expressing E2F + CycD/Cdk4 for H3K27Me3, H3K9Me3 and HP1 and found that clustering of facultative and constitutive heterochromatin was dramatically disrupted. We quantified facultative heterochromatin foci and found H3K27Me3 forming fewer, smaller and less intense foci (Fig. 7F-K). By contrast, HP1 levels became extremely high, with a diffuse localization throughout the nucleus (Fig. 7H, J), similar to the effects of E2F on HP1 at robust G0 (Fig. 6). These results demonstrate that heterochromatin clustering is a consequence of cell cycle exit rather than terminal differentiation. In addition, terminal differentiation can proceed despite a visibly significant disruption of heterochromatin organization.

\section{Discussion \\ The relationship between heterochromatin clustering and differentiation}

A number of studies have documented increased clustering and condensation of heterochromatin as cells differentiate [reviewed in 56]. In this study we reveal a substantial effect of the cell cycling status on heterochromatin clustering independent of differentiation. Heterochromatin clustering increases as the cell cycle slows and cells exit the cell cycle. By delaying or bypassing cell cycle exit in terminally differentiating cells, we show that the highly clustered state of heterochromatin in postmitotic cells is a consequence of cell cycle exit rather than the process of terminal differentiation. Importantly, we show that differentiation still proceeds even when cell cycle exit is prevented and heterochromatin clustering is severely disrupted (Fig. 7). We suggest this is because disrupting heterochromatin clustering has only limited effects on the expression of specific heterochromatinrepressed genes in the context of the Drosophila wing
(Fig. 4) and minimal effects on the terminal differentiation gene expression program. Indeed, we show that cell cycle exit can proceed normally in the Drosophila wing even when heterochromatin-dependent gene silencing is directly compromised (Fig. 2). Altogether this demonstrates that the increased heterochromatin clustering observed during differentiation is a consequence rather than a cause of cell cycle exit and raises questions regarding the function of increasing very long-range heterochromatin interactions and heterochromatin clustering in differentiation.

\section{What is the function of heterochromatin clustering?}

When we delay or bypass cell cycle exit, we visibly disrupt heterochromatin clustering. We find that this leads to very mild effects on the expression of only a small number of Polycomb target genes (Fig. 4), and we did not find significant de-repression of genes that are located in or near constitutive heterochromatin [57] (not shown). Our result is consistent with recent work showing that compromising some types of PcG clustering seems to have limited and selective effects on Polycomb target gene silencing [31]. However, the minimal effect of disrupting cell cycle exit on heterochromatin-dependent gene silencing is somewhat unexpected as the E2F1 gene was one of the early identified modifiers of position effect variegation (PEV), which is thought to be due to heterochromatin-dependent gene silencing through association with constitutive heterochromatin $[47,58,59]$. This suggests either the PEV assay is highly sensitive to even mild or selective changes in heterochromatin-dependent gene silencing or that this assay reads out changes in the chromatin state that are different from the silencing of the endogenous genes we examined. Indeed, there are additional possible functions for heterochromatin clustering beyond heterochromatindependent gene silencing. For example, heterochromatin clustering could facilitate DNA damage repair in postmitotic cells, which downregulate many DNA repair genes when they exit the cell cycle and become more reliant on error prone NHEJ [reviewed in 60]. Sequestration of heterochromatin may prevent inappropriate interactions and fusions. It has also been proposed that sequestration of heterochromatin could lead to an increased efficiency of gene activation for very highly expressed genes by reducing the availability of possible binding sites for specific 

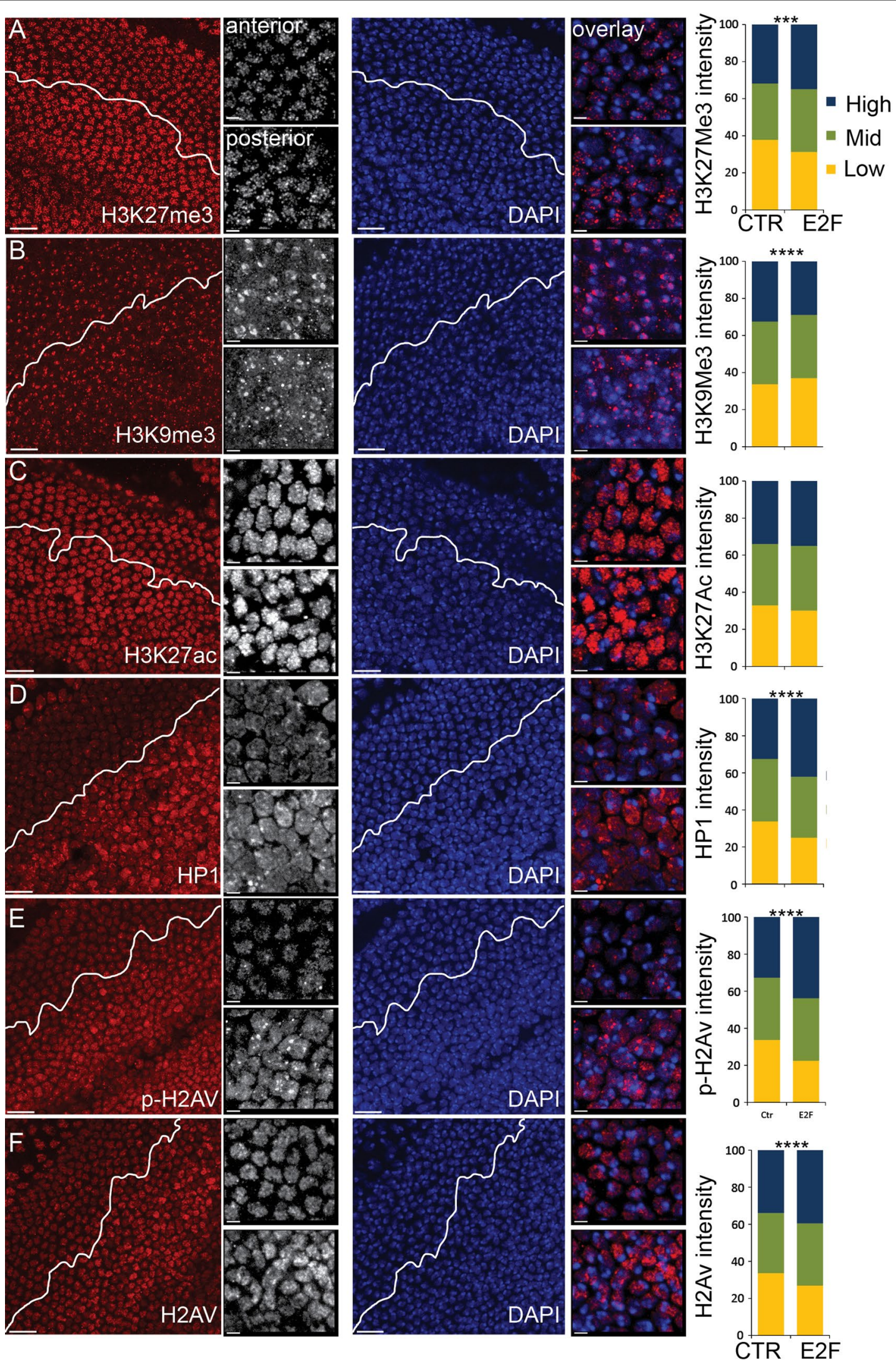
(See figure on previous page.)

Fig. 6 Robust G0 restores heterochromatin clustering and shares features with senescence. E2F was expressed in the posterior wing to delay cell cycle exit. At 42-44 h, when cells are in robust G0, wings were dissected and immunostained for the indicated histone modifications or chromatin binding proteins and DAPI to label nuclei $(\mathbf{A}-\mathbf{F})$. The distribution of staining intensity in 509-1185 nuclei, binned into three ranges, is shown at right. Robust G0 in the presence of high E2F increases H3K27Me3, HP1 and pH2Av, chromatin marks associated with senescence. $P$ values were determined by an unpaired $t$ test; ${ }^{* * *}<0.0001 ;^{* * *}<0.001$. Scale bars $=10 \mu \mathrm{m}$ in $\mathbf{A}-\mathbf{F}$ except for anterior $(\mathrm{A})$ and posterior $(\mathrm{P})$ zoomed images where the bar $=2 \mu m\left(e . g ., B_{A}, B_{p}\right)$

transcription factors [56] or could facilitate the formation of transcription factories [61].

A number of other studies also describe changes in the abundance of specific chromatin modifications associated with entry into or exit from G0. For example, $\mathrm{H} 3 \mathrm{~K} 9 \mathrm{Me} 3$ and $\mathrm{H} 3 \mathrm{~K} 27 \mathrm{Me} 3$ accumulate in postmitotic, differentiated cardiac muscle [37], while H4K16Ac and H3K27Ac increase in activated B cells exiting G0 [62]. While our data from the Drosophila wing suggest clustering of $\mathrm{H} 3 \mathrm{~K} 9 \mathrm{Me} 3$ and $\mathrm{H} 3 \mathrm{~K} 27 \mathrm{Me} 3$ domains during cell cycle exit rather than obvious changes in total levels, we do observe a strong upregulation of H4K16 acetylation when $\mathrm{G} 0$ is delayed by E2F activation, a situation similar to cell cycle reentry from G0. We also observe a decrease in H4K20Me3 when G0 is compromised, similar to what has been reported for quiescent human fibroblasts [63]. While H4K16Ac was not specifically measured in the fibroblast study, H4K20 methylation and H4K16 acetylation are antagonistic marks [64] and H4K16 acetylation can de-compact nucleosomes in vitro, although whether this also occurs in vivo has been questioned $[52,65]$. We suggest some aspects of chromatin remodeling, such as compaction and coalescence of heterochromatin (which may be tied to H4K16/20 dynamics) are shared among different contexts of cell cycle exit/reentry, while other chromatin changes associated with G0 entry/exit may be more cell-type specific.

\section{Why does delaying or bypassing cell cycle exit disrupt heterochromatin clustering in interphase?}

Our experiments effectively separate cell cycle exit from terminal differentiation to reveal that heterochromatin clustering is a consequence of cell cycle exit. Furthermore, heterochromatin clustering can be disrupted within a single cell cycle (Additional file 5: Fig. S4), suggesting progression through one round of S or M-phase is sufficient to disrupt heterochromatin clustering and long-range interactions. The effects we observe are not due to the dilution of chromatin marks by incorporation of new histones in S-phase, since we do not see changes in all histone marks (e.g., H3K4 methylation) or reduced global levels of histone marks in proliferating versus postmitotic cells (Additional file 3: Fig. S1). Indeed, when global levels of chromatin marks in actively proliferating fibroblasts were quantified and compared to fibroblasts held in G0 under contact inhibition for 14d, the majority of histone modifications did not exhibit significantly different levels [63]. This is likely because the levels of many histone modifiers are upregulated by positive cell cycle regulators through E2F transcriptional activity (Additional file 4: Table S1) which effectively coordinates increased histone modification with increased production and incorporation in S-phase.

Overexpression of E2F could have effects on chromatin modifications and condensation through sequestration or indirect inhibition of RB-family proteins via increased Cyclin/Cdk expression. RB associates with chromatin modifying complexes that promote facultative and constitutive heterochromatin formation [66-68]. RB also impacts chromosome condensation and cohesin levels at pericentromeric heterochromatin [69-71]. However, in our experiments during robust exit, E2F levels and transcriptional targets remain high while heterochromatin clustering and chromatin marks are restored (Fig. 6). This suggests that even if $\mathrm{RB}$ is inhibited by overexpression of E2F, the eventual entry into robust G0 somehow restores heterochromatin organization and chromatin modifications independent of RB.

During mitosis most transcription factors and chromatin modifiers are ejected from chromatin and higherorder architecture is lost [7]. This together with mitotic spindle assembly leads to the loss of long-range interactions and interchromosomal associations. These interactions are then restored, even in the presence of high E2F activity once cells engage additional mechanisms to exit the cell cycle during the robust G0 phase [46]. Our findings are in agreement with previous studies showing that the motion of heterochromatin domains and Polycomb bodies become more constrained as the cell cycle slows and cells exit the cell cycle $[16,17]$. We suggest that constrained motion combined with increased self-association or polymerization likely leads to the coalescence of heterochromatin after cell cycle exit.

Coalescence of heterochromatin can be driven by heterochromatin-bound proteins that self-associate such as HP1. HP1 has recently been shown to undergo phase separation to form liquid droplets that fuse when interphase becomes longer during Drosophila embryogenesis 

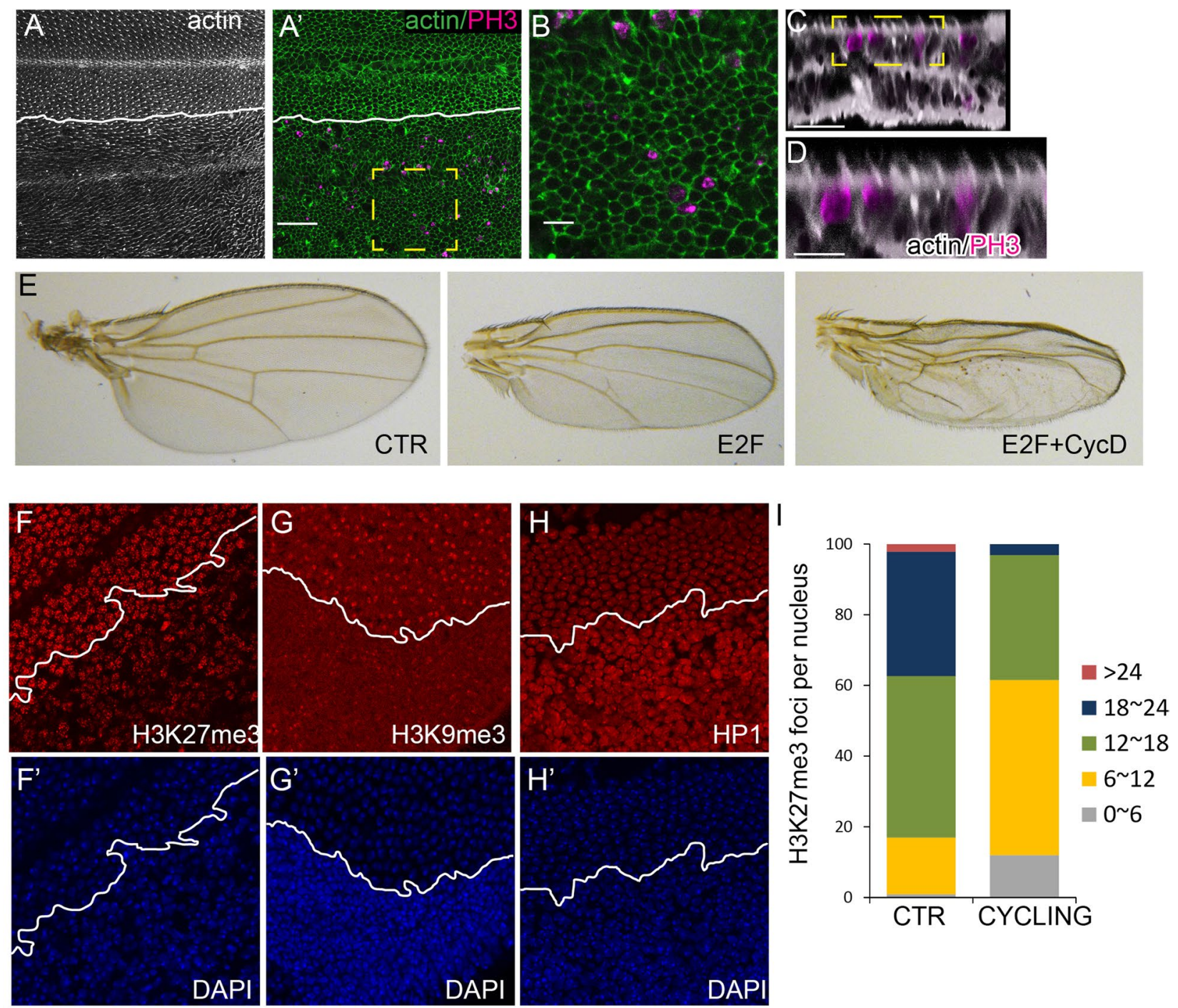

$J$

DAPI
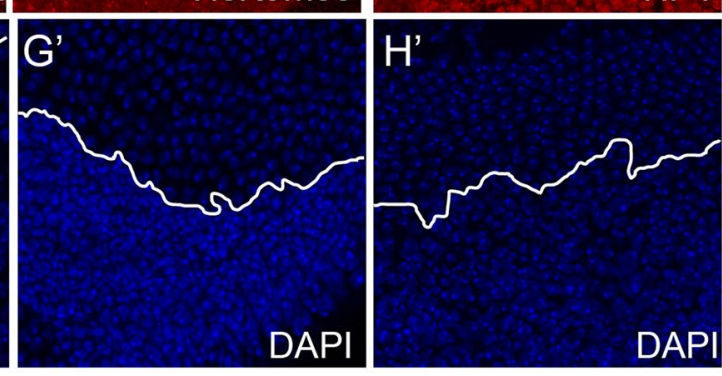

$\mathrm{K}$
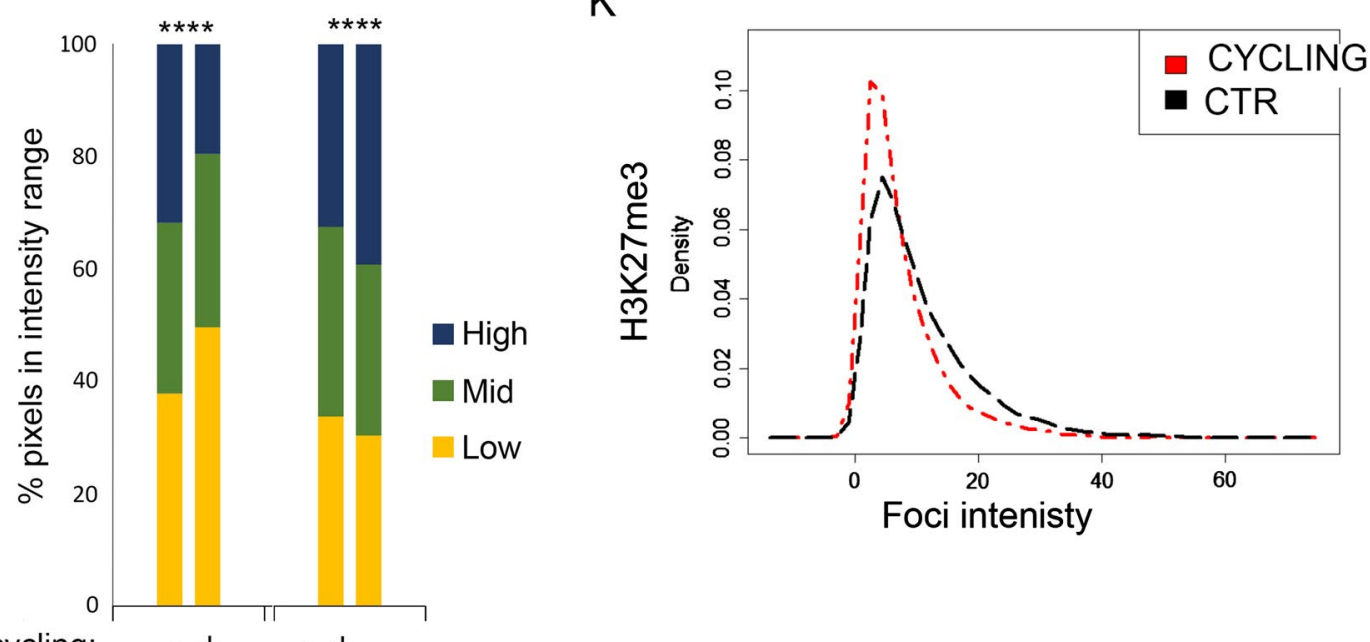

cycling:

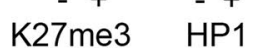


(See figure on previous page.)

Fig. 7 Heterochromatin clustering during terminal differentiation is a consequence of cell cycle exit. CycD, Cdk4 and E2F were co-expressed in the posterior wing to bypass robust cell cycle exit without preventing terminal differentiation. The anterior-posterior boundary is indicated by a white line. (A-D) Pupal wings at 42-44 h were dissected stained for actin and PH3 to label mitoses. Mitoses are evident in cells generating wings hairs, a hallmark of wing terminal differentiation $(\mathbf{E})$ and the wings generate intact adult wing cuticle. C, D showoptical cross sections $(x / z)$ of wings reveal $\mathrm{PH} 3$ and actin-rich hairs in the same section. $\mathbf{F}-\mathbf{K} \mathrm{CyCD}, \mathrm{Cdk} 4$ and E2F expression in the posterior wing prevents $\mathrm{G} 0$ entry and disrupts proper localization of heterochromatin-associated histone modifications and HP1. J The distribution of staining intensity in 474-1191 nuclei, binned into three ranges is shown. The reduced foci number ( $\mathbf{I}$ ) and intensity $(\mathbf{K})$ indicate compromised clustering of H3K27me3 containing chromatin when entry into G0 is prevented. $P$ values were determined by an unpaired $t$ test; ${ }^{* * *}<0.0001$. Scale bars $=10 \mu \mathrm{m}$ in $\mathbf{A}, 5 \mu \mathrm{m}$ in $\mathbf{B}$ and $2.5 \mu \mathrm{m}$ in $\mathbf{D}$

[72]. These droplets have been suggested to form diffusion barriers to limit heterochromatin access to factors involved in transcription such as TFIIB [73]. As the droplets fuse and mature during longer interphases, an immobile HP1 fraction forms. In our experiments to bypass cell cycle exit, we may limit the coalescence and maturation of HP1 droplets without preventing HP1 binding to H3K9me3. This could explain why dramatic effects on HP1 clustering may have minimal effects on gene de-repression. Alternatively, the role for HP1 clustering after cell cycle exit may largely affect silencing of transposons and piRNA clusters, an intriguing possibility to be addressed in future studies [74].

\section{Conclusions}

Heterochromatin clusters as cell exit the cell cycle and terminally differentiate. Delaying or preventing cell cycle exit disrupts heterochromatin clustering and globally alters chromatin modifications. Heterochromatin clustering during terminal differentiation is a consequence of cell cycle exit, rather than differentiation. Compromising heterochromatin-dependent gene silencing does not disrupt cell cycle exit.

\section{Additional files}

Additional file 1: Figure S2. Compromising PRC1 does not delay cell cycle exit. RNAi to Pc or white (as a control) was expressed in the posterior wing from the $L 3$ stage and postmitotic wings at 26-28 h were examined for mitoses as indicated by PH3 and effective knockdown of PRC 1 function by de-repression of the PRC1 target gene Ubx. Flow cytometry was also performed to measure cells that enter $S$ and $G 2$ phases. Green trace indicates cells from the posterior wing expressing the indicated transgenes. Black trace: control non-expressing anterior wing cells. Compromising PRC1 activity does not delay cell cycle exit. Scale bars $=100 \mu \mathrm{m}$.

Additional file 2: Figure S3. Two stages of G0 in differentiating wings. E2F was expressed in the posterior wing to delay cell cycle exit. $28 \mathrm{~h}$ and $42 \mathrm{~h}$ APF pupal tissues were dissected and immunostained for PH3 (to label mitoses) and E2F1. The anterior/posterior boundary is specified by the white line. Overexpression of E2F delays entry into G0 until $36 \mathrm{~h}$. At $42 \mathrm{~h}$ cells expressing high E2F1 are postmitotic (in robust G0). CycD/ $\mathrm{Cdk} 4+\mathrm{E} 2 \mathrm{~F}$ expression in the posterior wing is able to bypass the robust $\mathrm{G} 0$ to promote continued cycling, as shown by abundant mitoses ( $\mathrm{PH} 3)$ at $42 \mathrm{~h} . \mathrm{Bar}=50 \mu \mathrm{m}$.
Additional file 3: Figure S1. Global levels of histone modifications do not dramatically change at cell cycle exit. (A-D) Quantitative western blots were performed on wings of the indicated stages to assess the levels of modified or total histone H3 or HP1. Control (Ctrl) and E2F samples are from $28 \mathrm{~h}$ postmitotic wings overexpressing GFP or E2F respectively. Total H3K9Me3, H3K27Me3, and HP1 levels do not dramatically change with cell cycle exit, however they increase with E2F expression. Modifications associated with active chromatin, H3K4Me3 and H3K27Ac also do not dramatically change with cell cycle exit, but increase upon E2F expression.

Additional file 4: Table S1. Chromatin modifiers/organizers/remodelers that are upregulated upon E2F1/DP expression in pupal wings.

Additional file 5: Figure S4. Clustering of heterochromatin can be disrupted within one cell cycle. E2F was overexpressed in the posterior wing from $10 \mathrm{~h}$ APF. $12 \mathrm{~h}$ later (within approximately one cell cycle) tissues were immunostained for indicated histone modifications. The posterior region is labeled by the expression of GFP and the anterior/posterior boundary is specified by the white line. The distribution of staining intensity in 1112-1339 nuclei, binned into three ranges, is shown at bottom. E2F disrupts heterochromatin clustering within one cell cycle. $P$ values were determined by an unpaired $t$ test; ${ }^{* * * *}<0.0001$.

Additional file 6: Figure S5. Delaying cell cycle exit disrupts heterochromatin. (A) CycE/Cdk2 or CycD/Cdk4 complexes were overexpressed in the posterior wing from $0 \mathrm{~h} \mathrm{APF}$. The anterior/posterior boundary is indicated by the white line. At $28 \mathrm{~h}$ (flexible G0) or $42 \mathrm{~h}$ APF (robust G0) pupal tissues were dissected and immunostained for the indicated histone modifications. (B) The distribution of staining intensity from 492 to 976 nuclei, binned into three ranges, is shown. Wings expressing E2F or $\mathrm{CycD} / \mathrm{Cdk} 4$ to delay cell cycle exit were stained for mitoses (PH3) and the mitotic index at $27 \mathrm{~h}$ was quantified for the posterior compartment (C-D). The degree of heterochromatin disruption correlates with the number of cells cycling. $P$-values were determined by an unpaired $t$ test; ${ }^{* * * *} P$ value $<0.0001$.

Additional file 7: Table S2. Genes associated with senescence that are upregulated during robust $\mathrm{G} 0$ in the presence of ectopic E2F1/DP.

\section{Abbreviations}

G0: gap zero, exit from the cell cycle; G1: first gap phase of the cell cycle; S-phase: DNA synthesis phase; rDNA: ribosomal DNA; ITS: internal transcribed spacer; FISH: fluorescent in situ hybridization; L2: second larval instar; L3: third larval instar; h APF: hours after puparium formation; CDT: cell doubling time; DAPI: 4',6-diamidino-2-phenylindole; HP1: heterochromatin protein 1; H3K9: histone H3 lysine 9; H3K4: histone H3 lysine 4; H3K27: histone H3 lysine 27; H4K20: histone H4 lysine 20; H4K16: histone H4 lysine 16; H2Av: histone H2A variant; Me3: trimethylation; Ac: acetylation; PcG: Polycomb group; Pc: Polycomb; PRC1, PRC2: Polycomb repressive complexes 1 and 2; RNAi: RNA interference; RNAseq: high-throughput sequencing of cDNA libraries made from mRNA; FAIREseq: formaldehyde-assisted identification of regulatory elements with high-throughput sequencing; Gal80TS: temperature-sensitive Gal80; E(z): enhancer of zeste; Ubx: ultrabithorax; E2F/DP: E2 factor, transcription factor complex with dimerization partner; CycE, CycD: cyclins E or D; cdk: cyclin-dependent kinase. 


\section{Authors' contributions}

YM performed all experiments. YM and LB conceived of the project, analyzed the data and wrote the manuscript. Both authors read and approved the final manuscript.

\section{Acknowledgements}

A special thanks to Abbey Roelofs (University of Michigan, Advocacy and Research Support, LSA-IT) for developing the automatic quantification toolkit in MATLAB. We thank Dr. Yukiko Yamashita (University of Michigan, Ann Arbor) for sharing FISH reagents and protocols as well as D1 antibody. We thank Dr. Keith Maggert (Texas A\&M University) for sharing the Y10C reporter and Dr. Terry Orr-Weaver (Massachusetts Institute of Technology) for sharing the E2F1 antibody. Additional antibodies were obtained from Developmental Studies Hybridoma Bank (DSHB), created by the NICHD of the NIH and maintained at The University of lowa. Stocks obtained from the Bloomington Drosophila Stock Center (NIH P40OD018537) were used in this study.

\section{Competing interests}

The authors declare that they have no competing interests.

\section{Availability of supporting data}

The datasets supporting the conclusions of this article are available in GEO with accession numbers as follows; The RNAseq data are available with Accession No. GSE77562, the FAIREseq data are available with Accession No. GSE97956, and the microarray data are available with Accession No. GSE30484.

\section{Consent for publication}

All authors of the manuscript have read and agreed to its content and consent to publication.

\section{Ethical approval and consent to participate}

Not applicable.

\section{Funding}

This work in the Buttitta Lab was supported by the NIH (R21AG047931) and the American Cancer Society (RSG-15-161-01-DDC).

\section{Publisher's Note}

Springer Nature remains neutral with regard to jurisdictional claims in published maps and institutional affiliations.

Received: 5 September 2017 Accepted: 30 October 2017

Published online: 10 November 2017

\section{References}

1. Peric-Hupkes D, Meuleman W, Pagie L, Bruggeman SW, Solovei I, Brugman W, Graf S, Flicek P, Kerkhoven RM, van Lohuizen M, et al. Molecular maps of the reorganization of genome-nuclear lamina interactions during differentiation. Mol Cell. 2010;38(4):603-13.

2. Kohwi M, Lupton JR, Lai SL, Miller MR, Doe CQ. Developmentally regulated subnuclear genome reorganization restricts neural progenitor competence in Drosophila. Cell. 2013;152(1-2):97-108.

3. Clowney EJ, LeGros MA, Mosley CP, Clowney FG, Markenskoff-Papadimitriou EC, Myllys M, Barnea G, Larabell CA, Lomvardas S. Nuclear aggregation of olfactory receptor genes governs their monogenic expression. Cell. 2012:151(4):724-37.

4. Solovei I, Kreysing M, Lanctot C, Kosem S, Peichl L, Cremer T, Guck J, Joffe B. Nuclear architecture of rod photoreceptor cells adapts to vision in mammalian evolution. Cell. 2009;137(2):356-68.

5. Asp P, Blum R, Vethantham V, Parisi F, Micsinai M, Cheng J, Bowman C, Kluger Y, Dynlacht BD. Genome-wide remodeling of the epigenetic landscape during myogenic differentiation. Proc Natl Acad Sci USA. 2011:108(22):E149-58

6. Alabert C, Bukowski-Wills JC, Lee SB, Kustatscher G, Nakamura K, de Lima Alves F, Menard P, Mejlvang J, Rappsilber J, Groth A. Nascent chromatin capture proteomics determines chromatin dynamics during DNA replication and identifies unknown fork components. Nat Cell Biol. 2014;16(3):281-93.

7. Naumova N, Imakaev M, Fudenberg G, Zhan Y, Lajoie BR, Mirny LA, Dekker J. Organization of the mitotic chromosome. Science. 2013;342(6161):948-53.

8. Kadauke S, Blobel GA. Mitotic bookmarking by transcription factors Epigenet Chromatin. 2013;6(1):6.

9. Rice JC, Nishioka K, Sarma K, Steward R, Reinberg D, Allis CD. Mitoticspecific methylation of histone H4 Lys 20 follows increased PR-Set7 expression and its localization to mitotic chromosomes. Genes Dev. 2002;16(17):2225-30.

10. Liu W, Tanasa B, Tyurina OV, Zhou TY, Gassmann R, Liu WT, Ohgi KA, Benner C, Garcia-Bassets I, Aggarwal AK, et al. PHF8 mediates histone H4 lysine 20 demethylation events involved in cell cycle progression. Nature. 2010;466(7305):508-12.

11. Bracken AP, Pasini D, Capra M, Prosperini E, Colli E, Helin K. EZH2 is downstream of the pRB-E2F pathway, essential for proliferation and amplified in cancer. EMBO J. 2003;22(20):5323-35.

12. Chen S, Bohrer LR, Rai AN, Pan Y, Gan L, Zhou X, Bagchi A, Simon JA, Huang $\mathrm{H}$. Cyclin-dependent kinases regulate epigenetic gene silencing through phosphorylation of EZH2. Nat Cell Biol. 2010;12(11):1108-14.

13. Kaneko S, Li G, Son J, Xu CF, Margueron R, Neubert TA, Reinberg D. Phosphorylation of the PRC2 component Ezh2 is cell cycle-regulated and up-regulates its binding to ncRNA. Genes Dev. 2010;24(23):2615-20.

14. Wei Y, Chen YH, Li LY, Lang J, Yeh SP, Shi B, Yang CC, Yang JY, Lin CY, Lai CC, et al. CDK1-dependent phosphorylation of EZH2 suppresses methylation of H3K27 and promotes osteogenic differentiation of human mesenchymal stem cells. Nat Cell Biol. 2011;13(1):87-94.

15. Ahmed K, Dehghani H, Rugg-Gunn P, Fussner E, Rossant J, Bazett-Jones DP. Global chromatin architecture reflects pluripotency and lineage commitment in the early mouse embryo. PLoS ONE. 2010;5(5):e10531.

16. Thakar R, Csink AK. Changing chromatin dynamics and nuclear organization during differentiation in Drosophila larval tissue. J Cell Sci. 2005;118(Pt 5):951-60.

17. Cheutin T, Cavalli G. Progressive polycomb assembly on H3K27me3 compartments generates polycomb bodies with developmentally regulated motion. PLoS Genet. 2012;8(1):e1002465.

18. Buttitta LA, Katzaroff AJ, Perez CL, de la Cruz A, Edgar BA. A double-assurance mechanism controls cell cycle exit upon terminal differentiation in Drosophila. Dev Cell. 2007;12(4):631-43.

19. Schubiger M, Palka J. Changing spatial patterns of DNA replication in the developing wing of Drosophila. Dev Biol. 1987;123(1):145-53.

20. Milan M, Campuzano S, Garcia-Bellido A. Cell cycling and patterned cell proliferation in the Drosophila wing during metamorphosis. Proc Nat Acad Sci USA. 1996;93(21):11687-92.

21. Flegel K, Sun D, Grushko O, Ma Y, Buttitta L. Live cell cycle analysis of Drosophila tissues using the attune acoustic focusing cytometer and Vybrant DyeCycle violet DNA stain. J Vis Exp. 2013;75:e50239.

22. Guo Y, Flegel K, Kumar J, McKay DJ, Buttitta LA. Ecdysone signaling induces two phases of cell cycle exit in Drosophila cells. Biol Open. 2016:5(11):1648-61.

23. Sun D, Buttitta L. Protein phosphatase $2 A$ promotes the transition to G0 during terminal differentiation in Drosophila. Development. 2015;142(17):3033-45.

24. Johnston LA, Sanders AL. Wingless promotes cell survival but constrains growth during Drosophila wing development. Nat Cell Biol. 2003:5(9):827-33.

25. Reis T, Edgar BA. Negative regulation of dE2F1 by cyclin-dependent kinases controls cell cycle timing. Cell. 2004;117(2):253-64.

26. Riddle NC, Minoda A, Kharchenko PV, Alekseyenko AA, Schwartz YB, Tolstorukov MY, Gorchakov AA, Jaffe JD, Kennedy C, Linder-Basso D, et al. Plasticity in patterns of histone modifications and chromosomal proteins in Drosophila heterochromatin. Genome Res. 2011;21(2):147-63.

27. Aulner N, Monod C, Mandicourt G, Jullien D, Cuvier O, Sall A, Janssen S, Laemmli UK, Kas E. The AT-hook protein D1 is essential for Drosophila melanogaster development and is implicated in position-effect variegation. Mol Cell Biol. 2002;22(4):1218-32.

28. Figueiredo ML, Philip P, Stenberg P, Larsson J. HP1a recruitment to promoters is independent of H3K9 methylation in Drosophila melanogaster. PLoS Genet. 2012;8(11):e1003061. 
29. Loubiere V, Delest A, Thomas A, Bonev B, Schuettengruber B, Sati S, Martinez AM, Cavalli G. Coordinate redeployment of PRC1 proteins suppresses tumor formation during Drosophila development. Nat Genet. 2016:48(11):1436-42.

30. Gonzalez I, Mateos-Langerak J, Thomas A, Cheutin T, Cavalli G. Identification of regulators of the three-dimensional polycomb organization by a microscopy-based genome-wide RNAi screen. Mol Cell. 2014;54(3):485-99.

31. Wani AH, Boettiger AN, Schorderet P, Ergun A, Munger C, Sadreyev RI, Zhuang X, Kingston RE, Francis NJ. Chromatin topology is coupled to Polycomb group protein subnuclear organization. Nat Commun. 2016;7:10291.

32. Lavoie BD, Hogan $\mathrm{E}$, Koshland D. In vivo requirements for rDNA chromosome condensation reveal two cell-cycle-regulated pathways for mitotic chromosome folding. Genes Dev. 2004;18(1):76-87.

33. Freeman L, Aragon-Alcaide L, Strunnikov A. The condensin complex governs chromosome condensation and mitotic transmission of rDNA.J Cell Biol. 2000;149(4):811-24.

34. McKnight JN, Boerma JW, Breeden LL, Tsukiyama T. Global promoter targeting of a conserved lysine deacetylase for transcriptional shutoff during quiescence entry. Mol Cell. 2015;59(5):732-43.

35. Uyehara CM, Nystrom SL, Niederhuber MJ, Leatham-Jensen M, Ma Y, Buttitta LA, McKay DJ: Hormone-dependent control of developmental timing through regulation of chromatin accessibility. Genes Dev. 2017;31(9):862-75.

36. Blais A, van Oevelen CJ, Margueron R, Acosta-Alvear D, Dynlacht BD. Retinoblastoma tumor suppressor protein-dependent methylation of histone H3 lysine 27 is associated with irreversible cell cycle exit. J Cell Biol. 2007;179(7):1399-412.

37. Sdek P, Zhao P, Wang Y, Huang CJ, Ko CY, Butler PC, Weiss JN, Maclellan WR. Rb and p130 control cell cycle gene silencing to maintain the postmitotic phenotype in cardiac myocytes. J Cell Biol. 2011;194(3):407-23.

38. Panteleeva I, Boutillier S, See V, Spiller DG, Rouaux C, Almouzni G, Bailly D, Maison C, Lai HC, Loeffler JP, et al. HP1alpha guides neuronal fate by timing E2F-targeted genes silencing during terminal differentiation. EMBO J. 2007;26(15):3616-28.

39. Ma T, Van Tine BA, Wei Y, Garrett MD, Nelson D, Adams PD, Wang J, Qin J, Chow LT, Harper JW. Cell cycle-regulated phosphorylation of p220(NPAT) by cyclin $\mathrm{E} / \mathrm{Cdk} 2$ in Cajal bodies promotes histone gene transcription. Genes Dev. 2000;14(18):2298-313.

40. Zhao J, Kennedy BK, Lawrence BD, Barbie DA, Matera AG, Fletcher JA, Harlow E. NPAT links cyclin E-Cdk2 to the regulation of replicationdependent histone gene transcription. Genes Dev. 2000;14(18):2283-97.

41. Muller H, Bracken AP, Vernell R, Moroni MC, Christians F, Grassilli E, Prosperini E, Vigo E, Oliner JD, Helin K. E2Fs regulate the expression of genes involved in differentiation, development, proliferation, and apoptosis. Genes Dev. 2001;15(3):267-85.

42. Schwartz YB, Kahn TG, Nix DA, Li XY, Bourgon R, Biggin M, Pirrotta V. Genome-wide analysis of Polycomb targets in Drosophila melanogaster. Nat Genet. 2006;38(6):700-5.

43. Tolhuis B, de Wit E, Muijrers I, Teunissen H, Talhout W, van Steensel B, van Lohuizen M. Genome-wide profiling of PRC1 and PRC2 Polycomb chromatin binding in Drosophila melanogaster. Nat Genet. 2006;38(6):694-9.

44. Schuettengruber B, Cavalli G. Recruitment of polycomb group complexes and their role in the dynamic regulation of cell fate choice. Development. 2009;136(21):3531-42.

45. Korenjak M, Anderssen E, Ramaswamy S, Whetstine JR, Dyson NJ. RBF binding to both canonical E2F targets and noncanonical targets depends on functional dE2F/dDP complexes. Mol Cell Biol. 2012;32(21):4375-87.

46. Buttitta LA, Katzaroff AJ, Edgar BA. A robust cell cycle control mechanism limits E2F-induced proliferation of terminally differentiated cells in vivo. J Cell Biol. 2010;189(6):981-96.

47. Seum C, Spierer A, Pauli D, Szidonya J, Reuter G, Spierer P. Position-effect variegation in Drosophila depends on dose of the gene encoding the E2F transcriptional activator and cell cycle regulator. Development. 1996;122(6):1949-56.

48. Ho JW, Jung YL, Liu T, Alver BH, Lee S, Ikegami K, Sohn KA, Minoda A, Tolstorukov MY, Appert A, et al. Comparative analysis of metazoan chromatin organization. Nature. 2014;512(7515):449-52.
49. Schwaiger M, Stadler MB, Bell O, Kohler H, Oakeley EJ, Schubeler D. Chromatin state marks cell-type- and gender-specific replication of the Drosophila genome. Genes Dev. 2009;23(5):589-601.

50. Liu J, McConnell K, Dixon M, Calvi BR. Analysis of model replication origins in Drosophila reveals new aspects of the chromatin landscape and its relationship to origin activity and the prereplicative complex. Mol Biol Cell. 2012;23(1):200-12.

51. Shlyueva D, Stampfel G, Stark A. Transcriptional enhancers: from properties to genome-wide predictions. Nat Rev Genet. 2014;15(4):272-86.

52. Shogren-Knaak M, Ishii H, Sun JM, Pazin MJ, Davie JR, Peterson CL. Histone H4-K16 acetylation controls chromatin structure and protein interactions. Science. 2006;311(5762):844-7.

53. Di Micco R, Sulli G, Dobreva M, Liontos M, Botrugno OA, Gargiulo G, dal Zuffo R, Matti V, d'Ario G, Montani E, et al. Interplay between oncogeneinduced DNA damage response and heterochromatin in senescence and cancer. Nat Cell Biol. 2011;13(3):292-302.

54. Narita M, Nunez S, Heard E, Narita M, Lin AW, Hearn SA, Spector DL, Hannon GJ, Lowe SW. Rb-mediated heterochromatin formation and silencing of E2F target genes during cellular senescence. Cell. 2003;113(6):703-16.

55. Davidson JM, Duronio RJ. S phase-coupled E2f1 destruction ensures homeostasis in proliferating tissues. PLoS Genet. 2012;8(8):e1002831.

56. Meister P, Mango SE, Gasser SM. Locking the genome: nuclear organization and cell fate. Curr Opin Genet Dev. 2011;21(2):167-74.

57. Smith CD, Shu S, Mungall CJ, Karpen GH. The Release 5.1 annotation of Drosophila melanogaster heterochromatin. Science. 2007;316(5831):1586-91.

58. Harmon B, Sedat J. Cell-by-cell dissection of gene expression and chromosomal interactions reveals consequences of nuclear reorganization. PLoS Biol. 2005;3(3):e67.

59. Csink AK, Henikoff S. Genetic modification of heterochromatic association and nuclear organization in Drosophila. Nature. 1996;381 (6582):529-31.

60. Iyama T, Wilson DM 3rd. DNA repair mechanisms in dividing and nondividing cells. DNA Repair (Amst). 2013;12(8):620-36.

61. Van Bortle K, Corces VG. Nuclear organization and genome function. Annu Rev Cell Dev Biol. 2012;28:163-87.

62. Kieffer-Kwon KR, Nimura K, Rao SSP, Xu J, Jung S, Pekowska A, Dose $M$, Stevens E, Mathe E, Dong P et al. Myc regulates chromatin decompaction and nuclear architecture during B cell activation. Mol Cell. 2017;67(4):566-78.

63. Evertts AG, Manning AL, Wang X, Dyson NJ, Garcia BA, Coller HA. H4K2O methylation regulates quiescence and chromatin compaction. Mol Biol Cell. 2013:24(19):3025-37.

64. Nishioka K, Rice JC, Sarma K, Erdjument-Bromage H, Werner J, Wang Y, Chuikov S, Valenzuela P, Tempst P, Steward R, et al. PR-Set7 is a nucleosome-specific methyltransferase that modifies lysine 20 of histone $\mathrm{H} 4$ and is associated with silent chromatin. Mol Cell. 2002:9(6):1201-13.

65. Taylor GC, Eskeland R, Hekimoglu-Balkan B, Pradeepa MM, Bickmore WA. H4K16 acetylation marks active genes and enhancers of embryonic stem cells, but does not alter chromatin compaction. Genome Res. 2013;23(12):2053-65.

66. Ishak CA, Marshall AE, Passos DT, White CR, Kim SJ, Cecchini MJ, Ferwati S, MacDonald WA, Howlett CJ, Welch ID, et al. An RB-EZH2 complex mediates silencing of repetitive DNA sequences. Mol Cell. 2016;64(6):1074-87.

67. Gonzalo S, Blasco MA. Role of Rb family in the epigenetic definition of chromatin. Cell Cycle. 2005:4(6):752-5.

68. Isaac CE, Francis SM, Martens AL, Julian LM, Seifried LA, Erdmann N, Binne UK, Harrington L, Sicinski P, Berube NG, et al. The retinoblastoma protein regulates pericentric heterochromatin. Mol Cell Biol. 2006;26(9):3659-71.

69. Longworth MS, Herr A, Ji JY, Dyson NJ. RBF1 promotes chromatin condensation through a conserved interaction with the Condensin II protein dCAP-D3. Genes Dev. 2008;22(8):1011-24.

70. Manning AL, Longworth MS, Dyson NJ. Loss of pRB causes centromere dysfunction and chromosomal instability. Genes Dev. 2010;24(13):1364-76.

71. Longworth MS, Dyson NJ. pRb, a local chromatin organizer with global possibilities. Chromosoma. 2010;119(1):1-11.

72. Strom AR, Emelyanov AV, Mir M, Fyodorov DV, Darzacq X, Karpen GH. Phase separation drives heterochromatin domain formation. Nature. 2017;547(7662):241-5. 
73. Larson AG, Elnatan D, Keenen MM, Trnka MJ, Johnston JB, Burlingame AL, Agard DA, Redding S, Narlikar GJ. Liquid droplet formation by HP1alpha suggests a role for phase separation in heterochromatin. Nature. 2017:547(7662):236-40
74. Penke TJ, McKay DJ, Strahl BD, Matera AG, Duronio RJ. Direct interrogation of the role of H3K9 in metazoan heterochromatin function. Genes Dev. 2016;30(16):1866-80.

\section{Submit your next manuscript to BioMed Central} and we will help you at every step:

- We accept pre-submission inquiries

- Our selector tool helps you to find the most relevant journal

- We provide round the clock customer support

- Convenient online submission

- Thorough peer review

- Inclusion in PubMed and all major indexing services

- Maximum visibility for your research

Submit your manuscript at www.biomedcentral.com/submit
() Biomed Central 